\title{
Ionospheric scintillation over Antarctica during the storm of 5-6 April 2010
}

\author{
J. Kinrade, ${ }^{1}$ C. N. Mitchell, ${ }^{1}$ P. Yin,,${ }^{1,2}$ N. Smith, ${ }^{1}$ M. J. Jarvis, ${ }^{3}$ D. J. Maxfield, ${ }^{3}$ \\ M. C. Rose, ${ }^{3}$ G. S. Bust, ${ }^{4}$ and A. T. Weatherwax ${ }^{5}$ \\ Received 12 August 2011; revised 7 November 2011; accepted 28 November 2011; published 3 May 2012.
}

[1] On 5 April 2010 a coronal mass ejection produced a traveling solar wind shock front that impacted the Earth's magnetosphere, producing the largest geomagnetic storm of 2010. The storm resulted in a prolonged period of phase scintillation on Global Positioning System signals in Antarctica. The scintillation began in the deep polar cap at South Pole just over 40 min after the shock front impact was recorded by a satellite at the first Lagrangian orbit position. Scintillation activity continued there for many hours. On the second day, significant phase scintillation was observed from an auroral site $\left(81^{\circ} \mathrm{S}\right)$ during the postmidnight sector in association with a substorm. Particle data from polar-orbiting satellites provide indication of electron and ion precipitation into the Antarctic region during the geomagnetic disturbance. Total electron content maps show enhanced electron density being drawn into the polar cap in response to southward turning of the interplanetary magnetic field. The plasma enhancement structure then separates from the dayside plasma and drifts southward. Scintillation on the first day is coincident spatially and temporally with a plasma depletion region both in the dayside noon sector and in the dayside cusp. On the second day, scintillation is observed in the nightside auroral region and appears to be strongly associated with ionospheric irregularities caused by $E$ region particle precipitation.

Citation: Kinrade, J., C. N. Mitchell, P. Yin, N. Smith, M. J. Jarvis, D. J. Maxfield, M. C. Rose, G. S. Bust, and A. T. Weatherwax (2012), Ionospheric scintillation over Antarctica during the storm of 5-6 April 2010, J. Geophys. Res., 117, A05304, doi:10.1029/2011JA017073.

\section{Introduction}

[2] Solar disturbances can cause periods of geomagnetic and ionospheric disturbance that affect Global Navigation Satellite System (GNSS) signals. Signal refraction and diffraction via small-scale electron density structuring (tens of kilometers down to hundreds of meters) can result in amplitude and phase scintillation. Severe scintillation conditions pose significant problems to GNSS receivers, including signal power fading and phase jitter. GNSS scintillation is well known at equatorial latitudes [Basu et al., 2002] and has important implications for navigation. Reports of GNSS amplitude scintillation at high latitudes are less common; Smith et al. [2008] show an event associated with an auroral arc during a substorm. Phase scintillation is more common at high latitudes; for example, Mitchell et al. [2005] report

\footnotetext{
${ }^{1}$ Department of Electronic and Electrical Engineering, University of Bath, Bath, UK.

${ }^{2}$ College of Electronic Information Engineering, Civil Aviation University of China, Tianjin, China.

${ }^{3}$ Physical Sciences Division, British Antarctic Survey, Cambridge, UK.

${ }^{4}$ Atmospheric and Space Technology Research Associates, LLC, Boulder, Colorado, USA.

${ }^{5}$ Department of Physics, Siena College, Loudonville, New York, USA.

Copyright 2012 by the American Geophysical Union. 0148-0227/12/2011JA017073
}

phase scintillation on the edge of polar cap patches in the high European Arctic, and Ngwira et al. [2010] associate phase scintillation in the Antarctic with auroral electron precipitation. Burston et al. [2009] show evidence for both turbulence and the gradient drift instabilities for the production of electron density irregularities at high latitudes.

[3] The mechanisms causing scintillation in the high-latitude ionosphere are not always easy to trace. Plasma structuring is largely dependent on magnetic coupling between the Interplanetary Magnetic Field (IMF) and the Earth's magnetosphere [Hunsucker and Hargreaves, 2003]. Southward IMF (negative $B_{z}$ component) conditions set up a dualcell plasma convection system, with large-scale fast moving plasma enhancement "patches" flowing from the local dayside noon sector across the polar cap to the nightside. Return plasma flow is driven from the nightside back to the dayside dawn and dusk sectors. At the same time the enhancements are diminishing as they recombine with the neutral atmosphere. Prolonged periods of southward $B_{z}$ can transport plasma from the dayside middle to high latitudes across the polar cap. The enhanced region of total electron content (TEC) is often referred to as a "Tongue of Ionization" (TOI). Magnetic reconnection within the magnetotail can also inject particles into the nightside ionosphere producing substorm ionization up to many days after an initial solar wind shock front. Solar wind and IMF-driven geomagnetic events are 
highly variable, and interact with each hemisphere differently. Seasonal axial tilt and nonsymmetry in the geomagnetic field render the Arctic and Antarctic ionospheres subject to different effects for a given solar event.

[4] Global Positioning System (GPS) signals can be used to observe the ionosphere over a large area through inversion tomography techniques. With the current geographic distribution of some 50 GPS receivers across Antarctica, electron density structures of scale hundreds of kilometers across can be imaged. This is too low in spatial resolution to see structures directly responsible for GPS scintillation. Specialized GPS scintillation receivers have already been deployed for several years in the Arctic [Prikryl et al., 2010; Spogli et al., 2009]. This paper reports on results from a new network of dedicated GPS scintillation receivers deployed at high latitudes in the Antarctic during a geomagnetic storm.

\section{Instruments and Methods}

[5] In January 2010 a total of seven GPS scintillation receivers were deployed across the central plateau of the Antarctic continent at latitudes within the auroral zones and polar cap. The modified Novatel GSV4004 GPS receivers track up to 11 satellites simultaneously at $\mathrm{L} 1(1575.42 \mathrm{MHz})$ and L2 (1227.60 MHz) frequencies, measuring phase and amplitude changes at a sample rate of $50 \mathrm{~Hz}$. L1 amplitude and phase scintillation measurements are recorded in the form of the computed indices $\mathrm{S}_{4}$ and $\sigma_{\varphi}$, respectively [Van Dierendonck, 1999]. TEC is computed using differential carrier phase and pseudorange measurements.

[6] Scintillation indices are calculated from the "raw" L1 signal carrier phase and intensity data; the standard window is $60 \mathrm{~s}$, using 3000 samples of $50 \mathrm{~Hz}$ amplitude or phase data. Observations made at low sky-view elevation angles $\left(<20^{\circ}\right.$ above the local horizon) are removed to reject the most severe multipath. A cutoff minimum of $240 \mathrm{~s}$ continuous satellite contact or "lock" time is also required, accounting for the "settling" period of the receiver's phaselocked tracking loop (PLL). This filtering stage provides a level of confidence that the measured scintillation parameters are representative of true ionospheric conditions, while minimizing the impact from the local multipath environment and systematic receiver effects.

[7] In addition to the scintillation observations TEC maps were produced using a tomographic technique known as ionospheric imaging. Ionospheric imaging is a method to combine multidirectional observations to reveal the spatial and temporal morphology of electron density. GPS data is used as the input by calculation of the dual-frequency phase changes with time. Assimilation of multidirectional observations from multiple, geographically spaced dual-frequency GPS receivers can provide a measurement set on which to perform a tomographic inversion technique; this paper uses an adaptation of the Multi-Instrument Data Assimilation System (MIDAS) method developed by Spencer and Mitchell [2007] and the Ionospheric Data Assimilation Four-Dimensional (IDA4D) technique by Bust et al. [2004]. Although sparse in comparison with midlatitudes, GPS receiver coverage within high latitudes has been improving in recent years. Pokhotelov et al. [2010] identified a TOI structure within the Arctic polar cap using GPS tomography during the geomagnetic storm of 14-17 October 2002. The first large-scale ionospheric image reconstructions above Antarctica were only recently attempted, owing to the previously sparse distribution of dual-frequency GPS observation sites at auroral and polar latitudes. Yin et al. [2009] identified the formation and evolution of a TOI within the polar cap during a period of geomagnetic disturbance in February 2004; 17 ground-based receivers contributed to the reconstruction of electron density maps in MIDAS with the Weimer model for plasma convection, and the images verified with in situ particle data from the Challenging Minisatellite Payload (CHAMP) and Defense Meteorological Satellite Program (DMSP) satellites. In 2010 more receivers were available: 50 sites were chosen from the PoleNet and International GNSS Service (IGS) databases through the UNAVCO facility (online; see Acknowledgments). Figure 1a shows the distribution of GPS ground receivers that contributed the data used in this study; some site name labels have been omitted for clarity owing to the close proximity of several sites. Figure $1 \mathrm{~b}$ shows (for an example) the observed GPS raypath coverage during 5 April 2010, 16:00-17:00 UTC, projected on to the ionosphere at an altitude of $350 \mathrm{~km}$.

[8] The ionospheric electron density was reconstructed on a three-dimensional grid of resolution $4^{\circ}$ in latitude, $4^{\circ}$ in longitude and $40 \mathrm{~km}$ in altitude. The grid was formed around the equator prior to being transformed to the high latitudes using a rotation matrix, hence mitigating the problems that would be associated with longitudinal convergence toward the geographic pole in the unrotated case. The radial distribution of the ionosphere was defined as a mathematically modeled set of empirical orthogonal functions (EOF), thus reducing the number of unknown variables in the inversion problem to a set of basis function coefficients [Fremouw et al., 1997]. Electron density images were produced with 10 min GPS data samples using a tomographic space-time inversion, with subsequent extraction of instantaneous maps of vertical TEC. The inversion required regularization, which sought to minimize the rate of change of electron density gradients in space and time.

[9] Magnetic observations are presented from a number of instruments. IMF observations were obtained from the Advanced Composition Explorer (ACE) satellite monitoring solar wind, magnetic field and energetic particle activity at the first Lagrangian orbit position. Planetary 3-hourly $K p$ indices are used to indicate a general level of global geomagnetic disturbance, and were obtained from the Space Physics Interactive Data Resource (SPIDR). Provisional $A E$ (auroral electrojet) indices provide an indication of auroral magnetic activity, and were obtained from the World Data Centre for Geomagnetism, Kyoto.

[10] Energetic electron and proton particle data were obtained from the Defense Meteorological Satellites Program (DMSP) and Polar Operational Environmental Satellite (POES), a series of polar-orbiting weather satellites at orbital altitudes of $\sim 830-870 \mathrm{~km}$. Electron and ion spectrometer plots are used here to identify auroral and polar cap precipitation that could cause irregular electron density structuring and hence scintillation.

[11] GPS data taken from the Challenging Minisatellite Payload (CHAMP) and Gravity Recovery and Climate Experiment (GRACE) polar-orbiting satellites were used to produce track projections of vertical TEC to verify the 


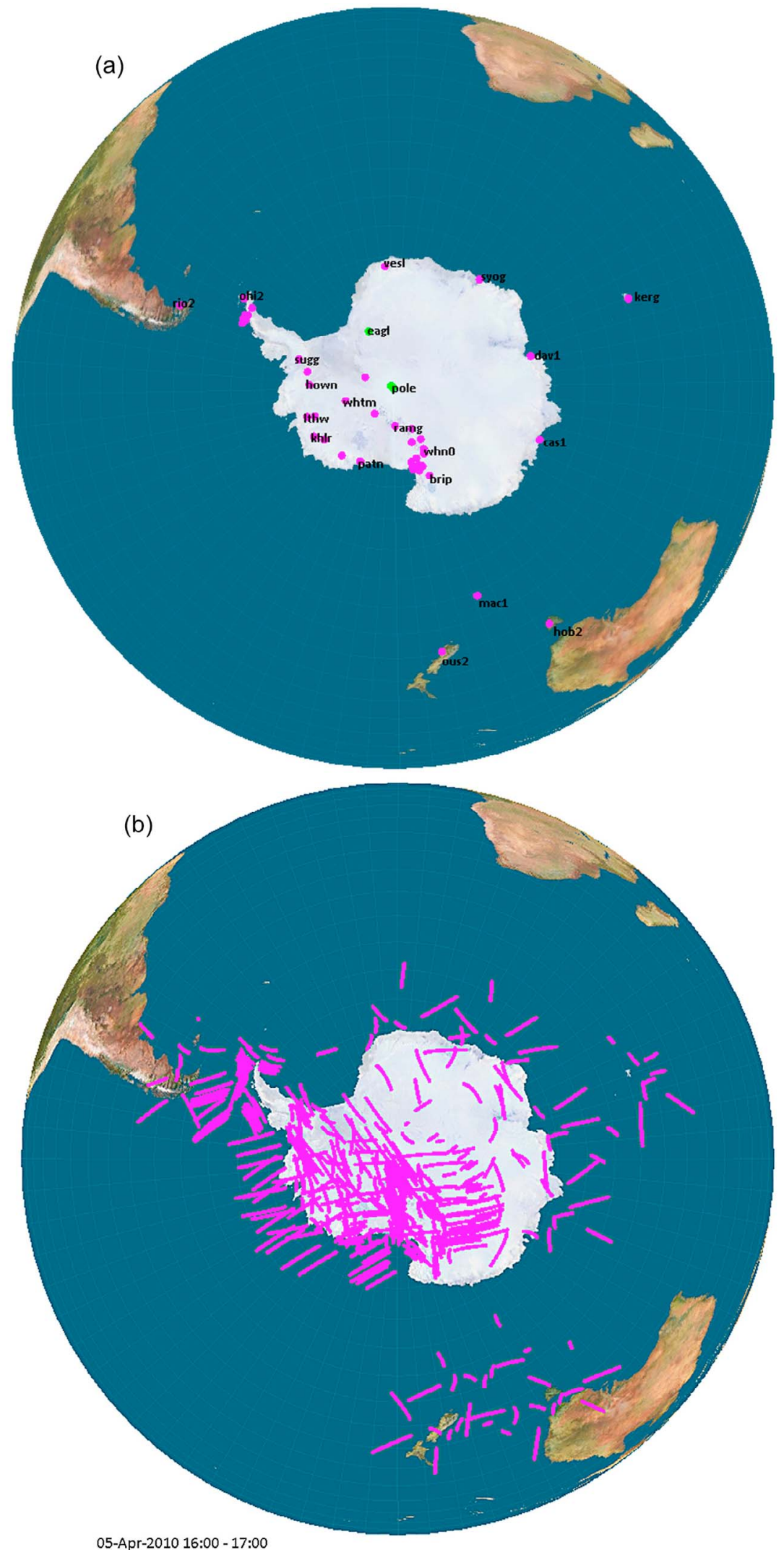

Figure 1. (a) The geographic distribution of GPS ground receiver sites used in this study and (b) an indication of observed GPS raypath coverage above $20^{\circ}$ horizon elevation within a typical 1 hour period, projected onto the ionosphere at $350 \mathrm{~km}$ altitude. Note that the raypath coverage is concentrated within the western and central continent and sparse over the oceans and northeastern continent. The two scintillation receiver locations are shown in green, at the geographic South Pole and remote site "Eagle" $\left(81^{\circ} \mathrm{S}, 22^{\circ} \mathrm{W}\right)$. 
presence of large-scale plasma gradients revealed through the inversion tomography.

\section{Observations and Analysis}

\subsection{IMF and Geomagnetic Activity}

[12] The period of geomagnetic disturbance during the 5 and 6 April 2010 was the focus of the study. A detailed account of the IMF conditions during this storm is provided by Möstl et al. [2010]. Figure 2 depicts a number of geomagnetic indicators within the period 5-7 April 2010. Figure 2 a shows the variation of 3-hourly $K p$ index that reached a peak value of 8 between 09:00 and 12:00 Coordinated Universal Time (UTC) on 5 April 2010. Figure 2b shows provisional levels of $A E$ index that reached a peak value of $2291 \mathrm{nT}$ at 09:20 UTC on 5 April 2010. Figures 2c2e present measurements from the ACE satellite; Figures $2 \mathrm{c}$ and $2 \mathrm{~d}$ show the orientation of the IMF components $B_{y}$ and $B_{z}$, respectively, over the duration of the disturbance, and Figure $2 \mathrm{e}$ is a record of solar wind velocity.

[13] From Figures 2c-2e it can be seen that a period of both fluctuation in the IMF and acceleration of solar wind velocity occurred on 5 April 2010. A shear in the solar wind speed at $\sim 07: 50$ UTC is strong indication of a traveling shock front, with the $V_{x}$ velocity component rising sharply from $\sim 500 \mathrm{~km}^{-1}$ to values above $700 \mathrm{~km}^{-1}$ in $\sim 30 \mathrm{~min}$. A maximum velocity of $816 \mathrm{~km}^{-1}$ was recorded at $\sim 13: 57 \mathrm{UTC}$, after which the wind speed remained high $\left(>600 \mathrm{~km}^{-1}\right)$ and gradually decelerated into the next day. The IMF was subject to sudden disturbance at $\sim 07: 55$ UTC, coincident with the solar wind velocity shear. The $B_{z}$ and $B_{y}$ components fluctuated strongly within the period $\sim 07: 55-10: 55$ UTC, switching orientation between negative and positive in the range $-18 \mathrm{nT}$ to $+15 \mathrm{nT}$. A period of sustained positive $B_{z}$ then occurred from $\sim 10: 55$ UTC, with values reaching up to $+21 \mathrm{nT}$. The main signature of the disturbance occurred at $\sim$ 12:00 UTC, with the $B_{z}$ and $B_{y}$ components rapidly switching polarity within a few minutes. The $B_{y}$ value fell significantly from $+9 \mathrm{nT}$ to $-22 \mathrm{nT}$, and remained negative for over 9 hours. The $B_{z}$ value dropped from $+21 \mathrm{nT}$ to $-2 \mathrm{nT}$, before settling into a prolonged undulating period between weakly negative and positive levels over the following 12 hours. Note that IMF conditions recorded at the ACE satellite position propagated to the magnetopause approximately $40 \mathrm{~min}$ later in time (ACE projection based on distance and solar wind velocity). A sudden peak signature in the $A E$ index at $\sim 09: 20$ UTC suggests that the auroral geomagnetic field responded to the shock front a little later in time; however the $A E$ index is based solely on Arctic magnetic observations and therefore is not representative of the southern high latitudes.

\subsection{Phase Scintillation}

[14] Scintillation data were analyzed for the period of geomagnetic disturbance. Figures $3 a$ and $3 b$ present a 2 day record of the $1 \mathrm{~min}$ scintillation indices from the receiver located at the geographic South Pole $\left(\sim 74^{\circ} \mathrm{S}\right.$ corrected geomagnetic [CGM] latitude), and site Eagle $\left(81^{\circ} \mathrm{S} 22^{\circ} \mathrm{W}\right.$, $\sim 67^{\circ} \mathrm{S}$ CGM latitude). An extended period of elevated $\sigma_{\varphi}$ index was prominent between $\sim 08: 30-18: 30$ UTC on 5 April 2010. It is interesting to note the short time of just over $40 \mathrm{~min}$ between the event at the ACE satellite and the onset of scintillations, indicating that the scintillation closely followed the arrival of the event at the magnetopause. Phase scintillation indices reached values of up to 0.55 , indicating only moderate signal phase angle variation; however it is interesting to note that the majority of observed satellites were subject to scintillation over a period spanning 10 hours. There is little evidence of associated amplitude scintillation during this time, with only a slight rise in the $\mathrm{S}_{4}$ index base level notable between $\sim$ 10:00-14:00 UTC. This predominance of phase rather than amplitude scintillation would indicate larger-scale (above the Fresnel scale of one to a few hundred meters at GPS signal frequencies) structures being responsible for most of the scintillation [Yeh and Liu, 1982].

[15] Each image in Figure 4 shows an hourly representation of tomographic vertical TEC over Antarctica during 5 April 2010, overlaid with $250 \mathrm{~km}$ intercepts of L1 phase scintillation indices from two GPS receivers - one at the geographic South Pole and the other at site Eagle $\left(81^{\circ} \mathrm{S}\right.$ $22^{\circ} \mathrm{W}$ ). For reference the TEC images have been smoothed in postprocessing. The time indicates the center of the imaging window used to produce the vertical TEC reconstructions, while scintillation points are overlaid from within the hour shown; for example, the 16:30 UTC image represents a TEC reconstruction overlaid with scintillation recordings from 16:00 to 17:00 UTC. The series of TEC images, color mapped in units of 1 TECU $=10^{16} \mathrm{el} / \mathrm{m}^{2}$, shows the formation of a TEC patch structure over the Western Antarctic. Interestingly, the structure's initial formation is relatively coincident with the switch of the IMF $B_{z}$ and $B_{y}$ at 12:00 UTC, seen in the 12:30 UTC image. The plasma structure is well formed over the "western" Antarctic by 16:30 UTC, but there is a dip in the density in a region associated with moderate scintillation. This region is interesting because it lies in the region of sunlit plasma and for some reason, there is a decrease in density over a localized area, and then further inside the convection region there is an increase in TEC.

[16] During the hour beginning 17:00 UTC the structure then separates from the original body of plasma $\left(-30^{\circ} \mathrm{E}\right.$, $-72^{\circ} \mathrm{N}$ ), displaying estimated TEC levels of up to $\sim 20$ TECU $\left(-90^{\circ} \mathrm{E},-81^{\circ} \mathrm{N}\right)$. A defined plasma gradient lies approximately along the solar terminator line, from $-180^{\circ} \mathrm{E}$ to $-30^{\circ} \mathrm{E}$ longitude. It is possible that this enhancement is sustained by its prolonged period in the sunlight. By 18:30 UTC the midlatitude plasma has receded away from the Antarctic, and the separate structure has started to drift westward and dissipate. The 19:30 UTC image suggests that the ionosphere has almost returned to a quiet, smooth state across most of the continent.

[17] $K p$ remained high on 6 April 2010, when it is likely that the magnetosphere was still being influenced by the interplanetary magnetic cloud following the shock front on 5 April 2010. The phase scintillation indices recorded at South Pole (Figure 3a) and markedly site Eagle (Figure 3b) suggest this also, with "burst" periods occurring across all observed satellites throughout 6 April 2010. The TEC image sequence of Figure 5 suggests relatively quiet plasma conditions, and there is no evidence of any polar cap or auroral structuring. Interestingly, this implies that in this instance and on the basis of the GPS inversion results, the phase scintillation indices were not associated temporally or spatially with any TEC gradients of plasma structuring. In fact 
(a) PLANETARY KP INDICES - 05-07 APRIL 2010

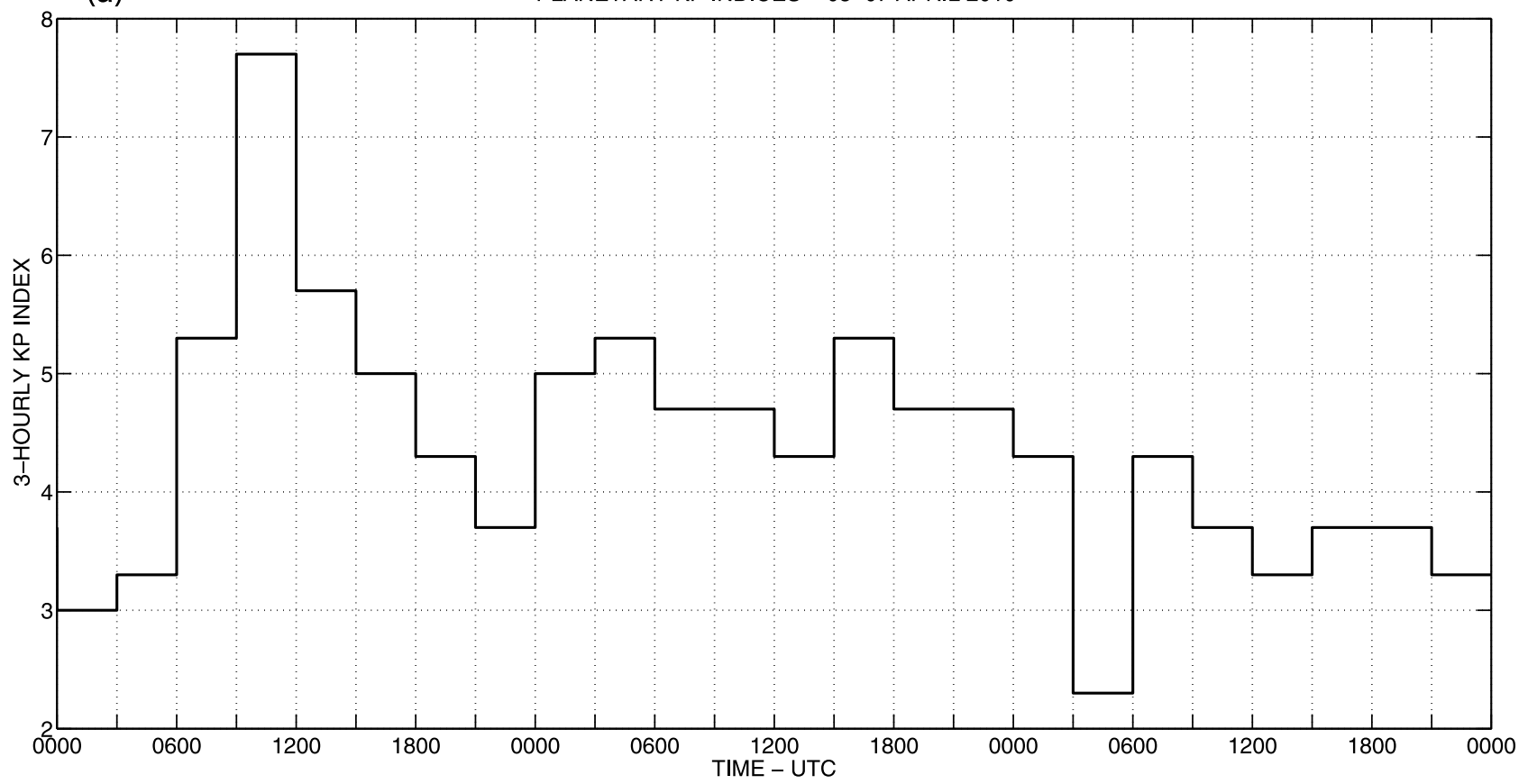

(b) PROVISIONAL 1-MIN KYOTO AE INDEX - 05-07 APRIL 2010

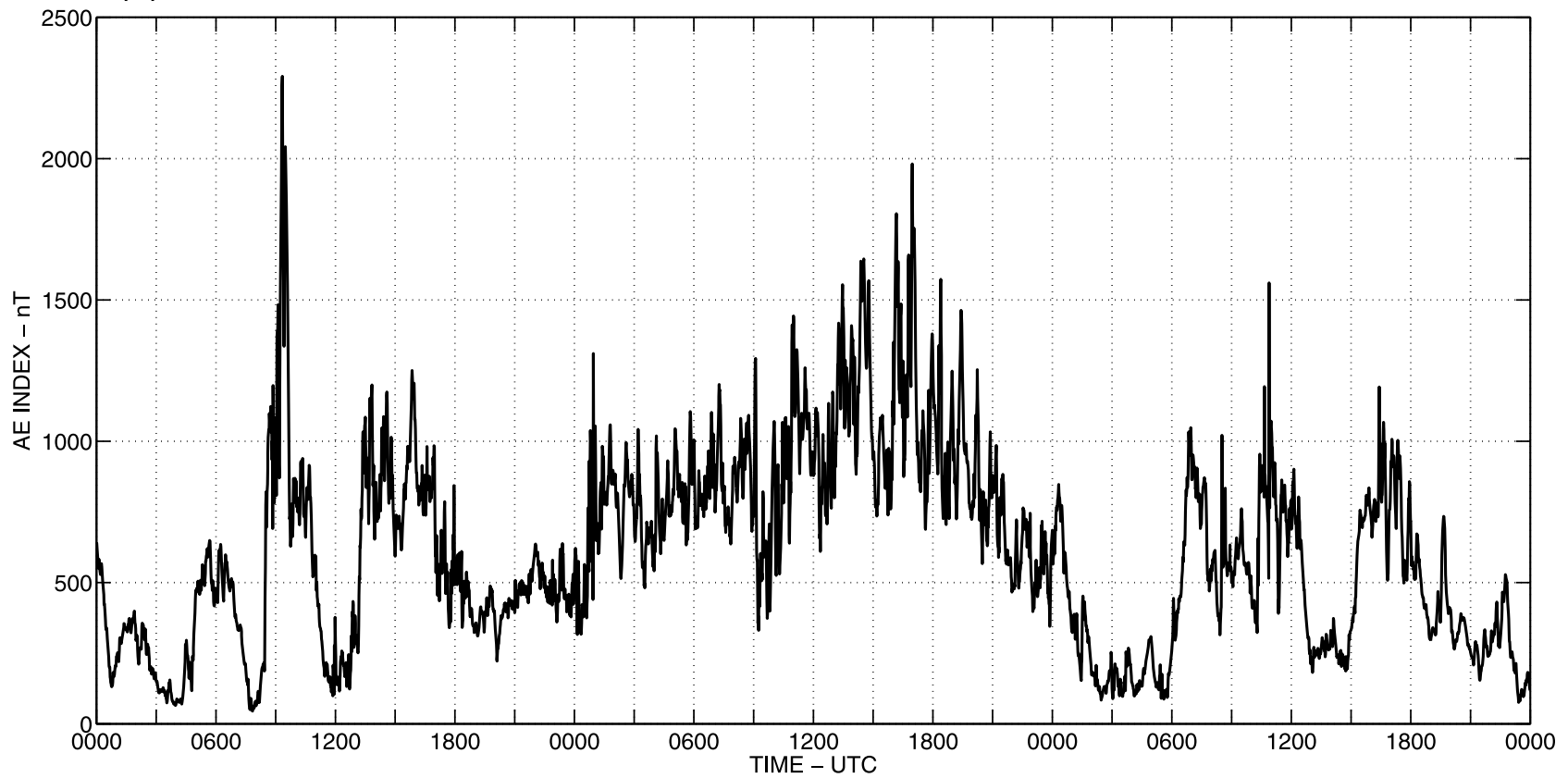

Figure 2. (a-e) Geomagnetic indicators and IMF measurements during the period of 5-7 April 2010. The variation of magnetic activity indices $K p$ (Figure $2 \mathrm{a}$ ) and $A E$ (Figure $2 \mathrm{~b}$ ) show the geomagnetic storm and substorm phases during days 5-7. The IMF components at the ACE satellite position (geocentric solar magnetospheric (GSM) plane) are perturbed, with signatures visible in both $B_{y}$ (Figure $2 \mathrm{c}$ ) and $B_{z}$ (Figure 2d). A record of solar wind velocity at the ACE satellite position (geocentric solar ecliptic (GSE) plane) (Figure 2e) reveals a traveling shock front at 07:50 UTC on 5 April 2010.

the scintillation region of the ionosphere was in darkness during this period.

\section{Ionospheric Conditions Leading to Scintillation}

[18] The presence of ionospheric scintillation at high latitudes is typically attributed to some form of irregular plasma structuring, and subsequent signal refraction and diffraction. In this section we present cases for the presence of both energetic particle precipitation and large-scale plasma structures as catalysts for the observed GPS phase scintillation during the period of study. 
(c) ACE SATELLITE 1-SEC GSM MAG DATA - By COMPONENT - 05-07 APRIL 2010

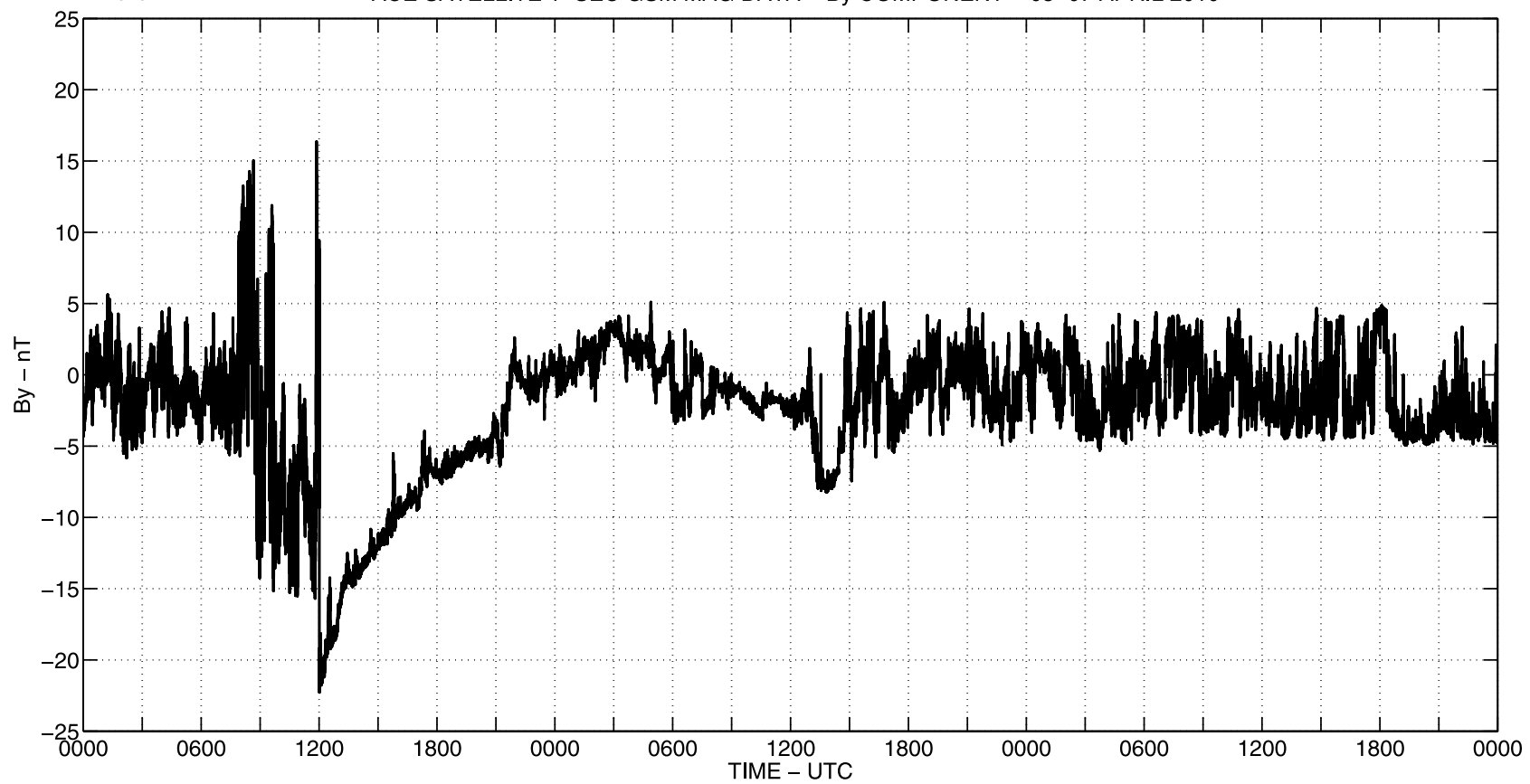

(d)

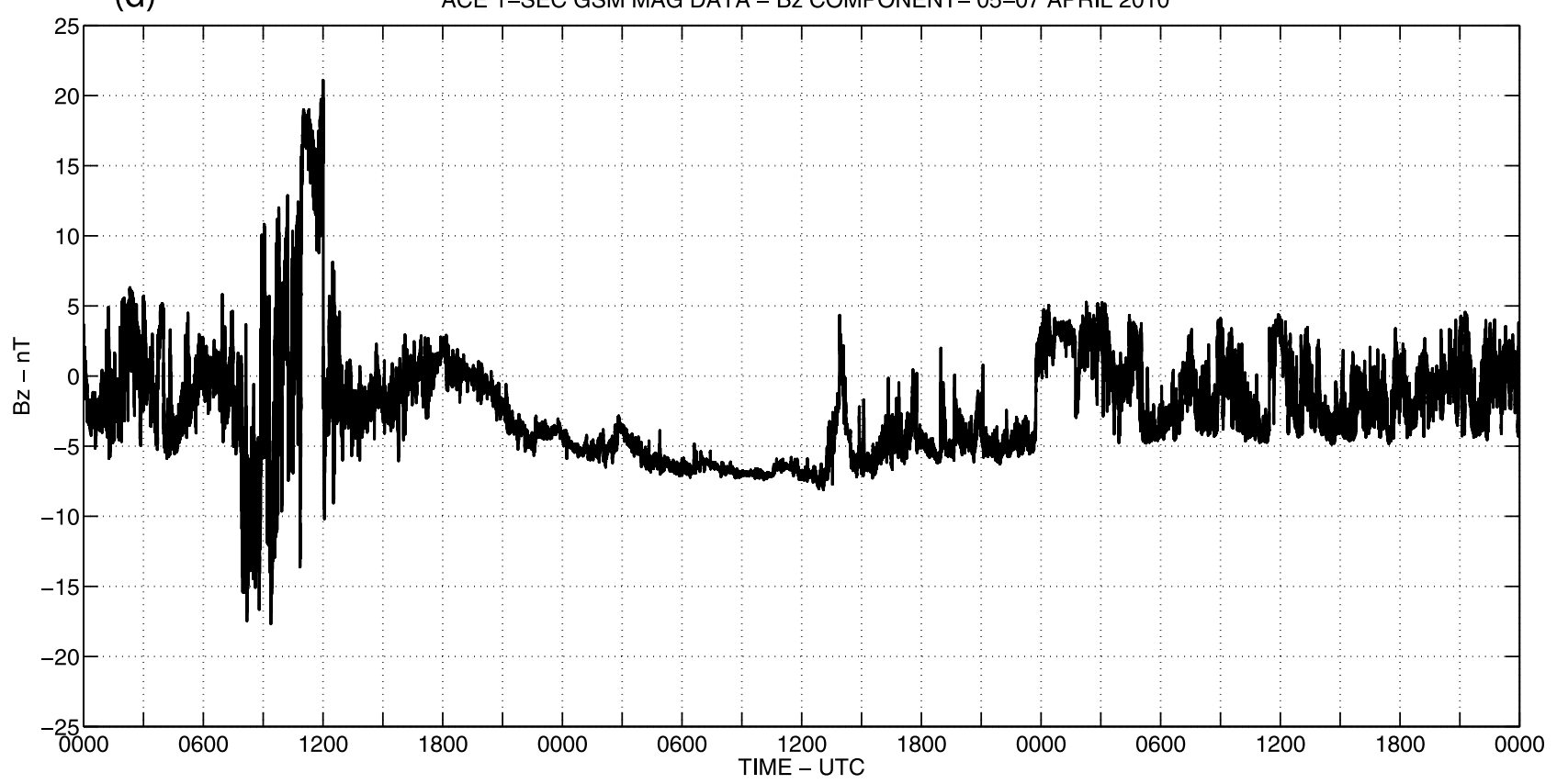

Figure 2. (continued)

\subsection{Particle Precipitation}

[19] We focused our attention on two periods of interest. The first period was the $\sim 16: 30$ UTC time period on 5 April 2010 (see Figure 4). During this period, South Pole and site Eagle $\left(81^{\circ} \mathrm{S} \mathrm{W} 22^{\circ}\right)$ were both in the magnetic local noon sector at $\sim(12: 30,13: 10)$ MLT, respectively, while South Pole was at $\sim 74^{\circ} \mathrm{S}$ corrected geomagnetic (CGM) latitude and Eagle was at $\sim 67^{\circ} \mathrm{S}$ CGM latitude. Both the South Pole GPS receiver and the Eagle GPS receiver showed significant scintillations, but in two significantly different magnetic latitude sectors; South Pole would typically have been considered to be in the dayside cusp region while Eagle would have been in the dayside auroral zone, although magnetic storm conditions can alter the cusp and auroral boundaries. The second period of interest was the $\sim 07: 30$ UTC period on 6 April 2010 (Figure 5). Again, both stations showed significant scintillations. However, they were then in the magnetic local midnight sector, and there was very little large-scale structuring at all. Thus, it appears that the observations indicate three distinctly separate scintillation events, with differing geophysical conditions. 


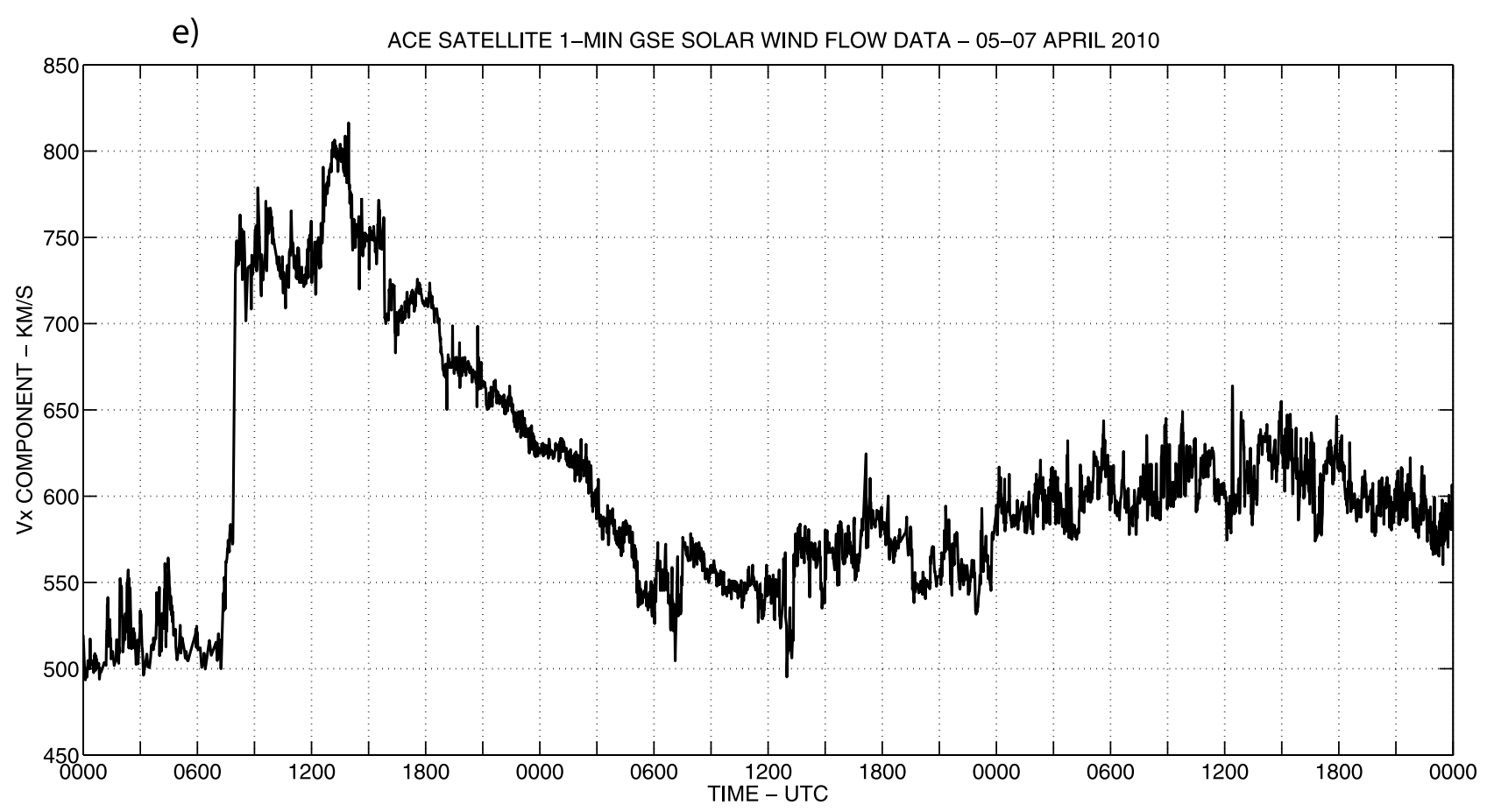

Figure 2. (continued)

[20] The first event was the 16:30 UTC period for the South Pole scintillations. These scintillations were located near the dayside cusp. Over the 1 hour period from 16:00 to 17:00 UTC, four separate satellites observed scintillations, with three satellites observing two separate periods of scintillations over the 1 hour period. Of the total seven scintillation periods, five of them exhibited very similar properties. Each scintillation event consisted of a short burst of phase fluctuations that lasted $\sim 30 \mathrm{~s}$. Within the $30 \mathrm{~s}$ burst there were several pseudoperiodic oscillations that lasted $\sim 5-6 \mathrm{~s}$. Each of the scintillation bursts were located in local magnetic time near 13:00 MLT, and at a magnetic latitude of 73$74^{\circ} \mathrm{S}$. In addition, the amplitude of each of the scintillation events varied by $3-4 \mathrm{~dB}$ over the $30 \mathrm{~s}$ period, indicating that the source was likely diffractive in nature. These similar characteristics indicate a single source of the scintillations located near 13:00 MLT, $73-74^{\circ} \mathrm{S}$ latitude and extending in time for at least $30 \mathrm{~min}$. It seems likely this source region was due to cusp precipitation of some kind. However, without correlative data this must remain only a plausible supposition. Figure 6 presents a representative example over a $200 \mathrm{~s}$ period for one of the $30 \mathrm{~s}$ burst events for PRN 4. The phase scintillations have been filtered with a sixth-order Butterworth filter (with $0.1 \mathrm{~Hz}$ cutoff frequency). The short burst of scintillations is similar for all five events.

[21] The second event was the 16:30 UTC period for the Eagle scintillations. These scintillations were located in or near an electron density depletion region at $\sim 70^{\circ} \mathrm{S}$ geographic latitude and $\sim 330^{\circ} \mathrm{W}$ longitude. This depletion region appeared at the "break-off" point of the plasma enhancement, between the solar-produced dayside plasma and the resulting patch-like body of enhancement that drifted southward. There are three interesting questions regarding this event. First, what was the cause of a density depletion region, at local noon, which was in a sunlit region? Second, what was the cause of the phase scintillations and third were the physical causes of the density depletions and scintillations linked? To help in answering these questions, Figure 7 presents a pass of DMSP 17 over Antarctica from 16:10 to 16:15 UTC. The third panel down presents the electron energy and energy flux along the pass, while the fourth panel presents the ion energy and energy flux. Unfortunately, this pass was in the $\sim 16: 00$ MLT sector rather than the 13:00 MLT sector of the observations. However, it is at least possible that the precipitation observed by DMSP in this sector was similar to precipitation events at $\sim 03: 00 \mathrm{MLT}$ away, considering the same magnetic latitude regions. If we focus on the elevated red electron precipitation from the time 16:12 UTC for $\sim 35 \mathrm{~s}$, we notice electron precipitation with $>1 \mathrm{KeV}$ energies and large energy fluxes. This would imply fairly hard $E$ region precipitation. In addition, the proton precipitation in the same time period showed 1$10 \mathrm{KeV}$ energies which were also $E$ region. During this period the magnetic latitudes were $\sim 70-68^{\circ} \mathrm{S}$, which is very similar to the Eagle magnetic latitudes. Particle data from the POES N18 satellite also showed strong electron precipitation and some proton precipitation in the $\sim 1400$ MLT sector (geographic longitude $344.7^{\circ}$, latitude $69.9^{\circ} \mathrm{S}$ at $\sim 16: 38$ UTC), lending further support to the suggestion of precipitation energy spread over the entire postnoon sector. Thus it seems likely that the Eagle phase scintillations manifested as a result of mixed plasma structuring; kilometer-scale (or larger) $E$ region precipitation irregularities, and large-scale plasma density gradients associated with the enhancement structure break off. However, there was also significant $<1 \mathrm{KeV}$ soft electron precipitation especially at $\sim 16: 12$ UTC. This was probably $F$ region precipitation, and was located at similar geomagnetic latitudes to the large density depletion observed in Figure 4. It is possible that the $F$ region precipitation had elevated the electron and ion temperatures, which 
(a)

SOUTH POLE RECEIVER - ALL OBSERVED SATELLITES >20 DEGREES ELEVATION - 05-06TH APRIL 2010

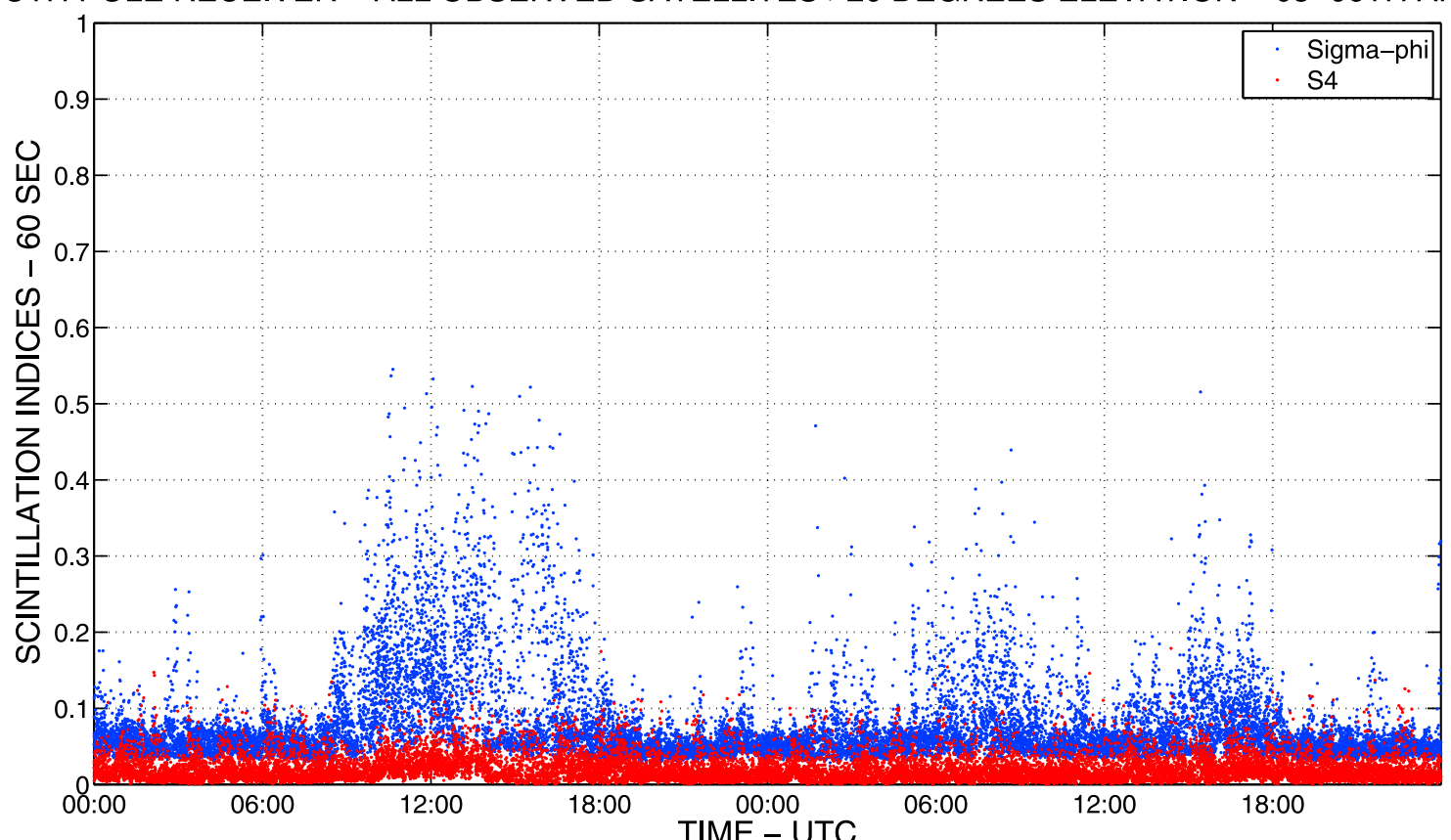

(b)

EAGLE NE RECEIVER - ALL OBSERVED SATELLITES >20 DEGREES ELEVATION - 05-06TH APRIL 2010

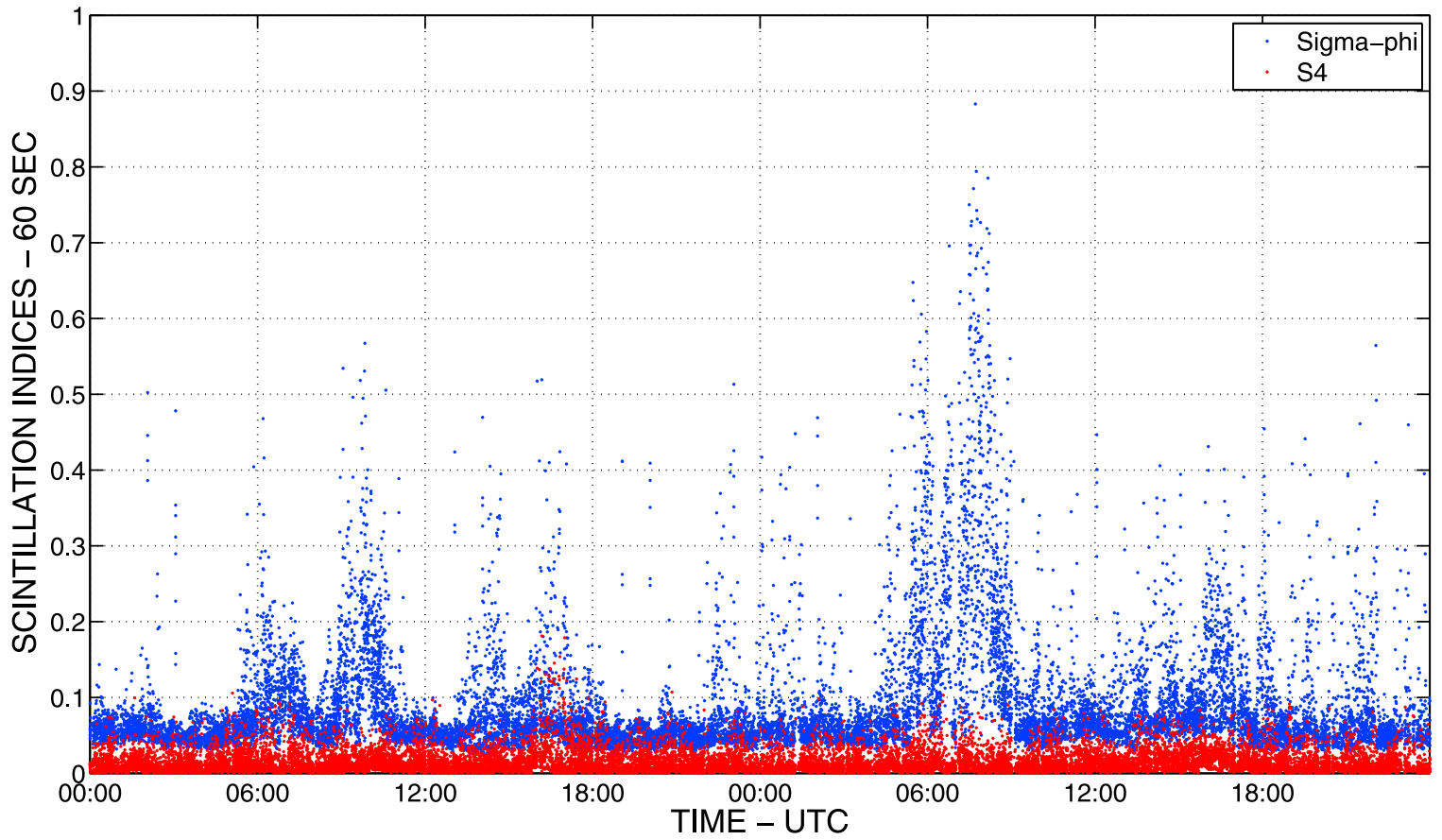

Figure 3. Amplitude and phase scintillation indices during 5-6 April 2010 at (a) South Pole and (b) site Eagle. Note the almost immediate onset of phase scintillation with the coronal mass ejection (CME) shock front, particularly at South Pole. The lack of significant amplitude scintillation indicates that the ionospheric irregularities present are of sizes larger than the first Fresnel radius of one to a few hundred meters at GPS frequencies ( $E$ and $F$ regions, respectively).

would lead to enhanced recombination of $\mathrm{O}^{+}$, and thus reduced electron densities. Valladares et al. [1994] show evidence for this mechanism causing multiple TOI break-off events in the northern high latitudes.
[22] The third event of interest was on 6 April 2010, from 06:00 to 08:00 UTC, and is represented in Figure 5. Here there was significant phase scintillation on a number of different satellites from both Eagle and South Pole. During 
(a)

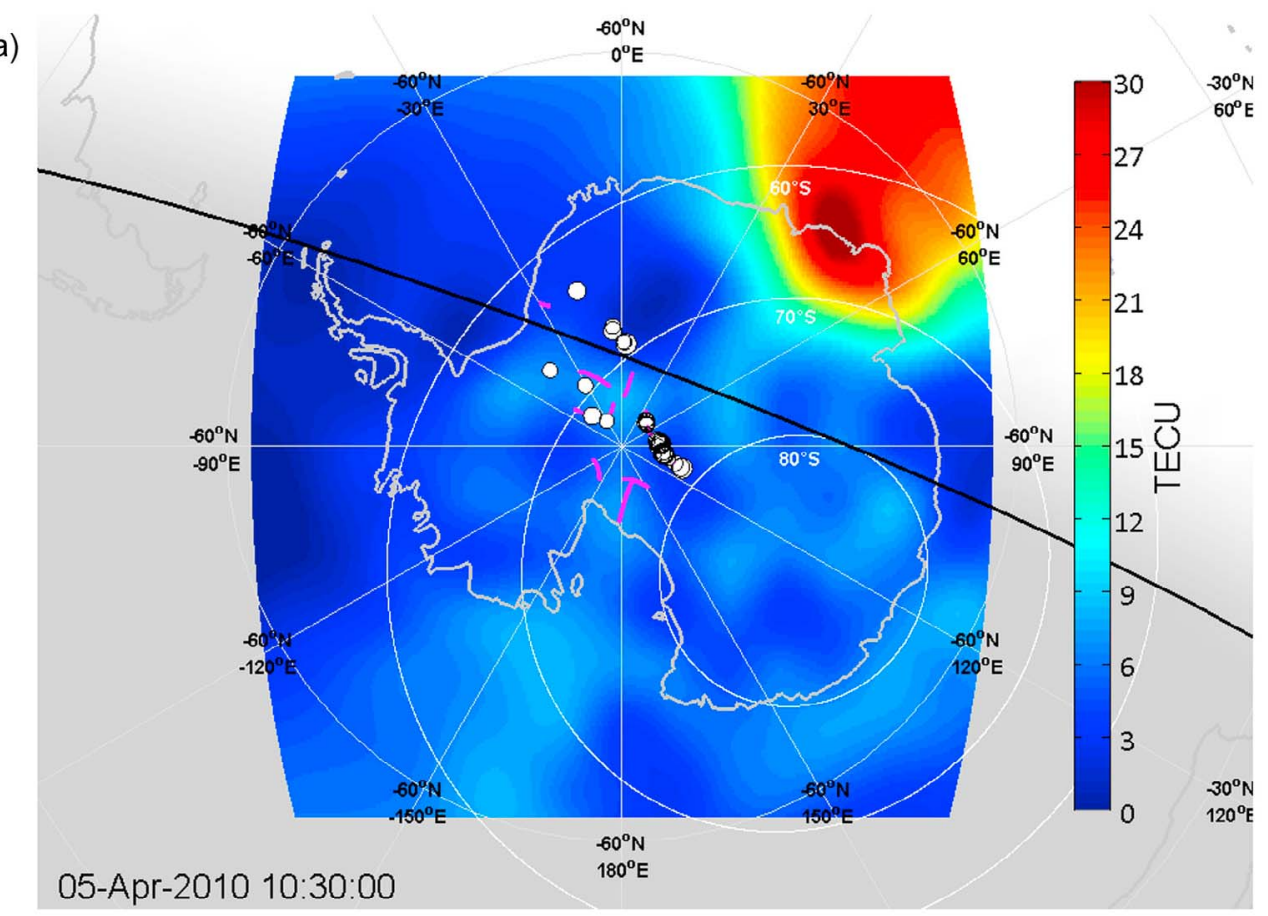

(b)

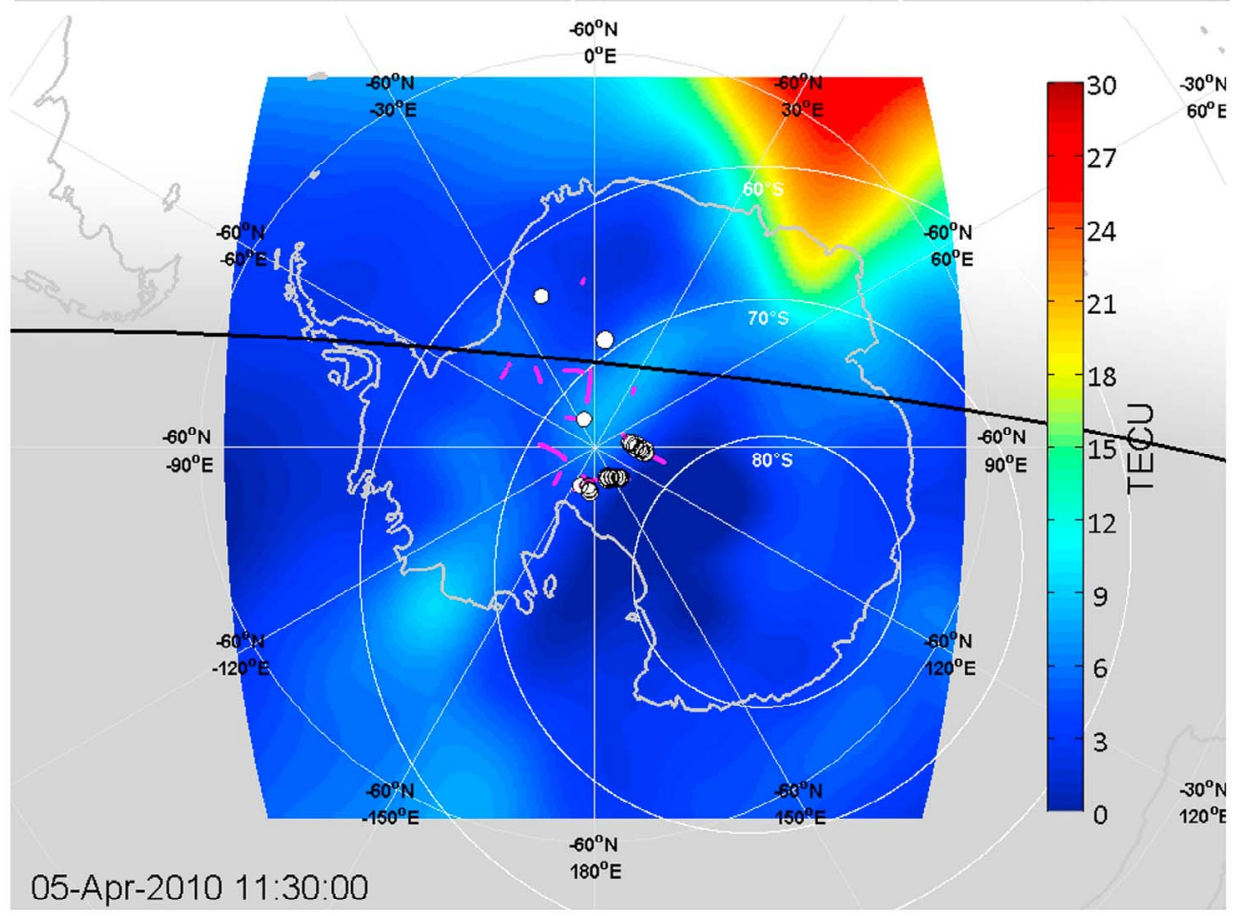

Figure 4. (a-j) Combined GPS vertical TEC images and GPS L1 phase scintillation occurrence as observed from receivers at the geographic South Pole and site Eagle $\left(81^{\circ} \mathrm{S}, 22^{\circ} \mathrm{W}\right)$ on 5 April 2010. Sun orientation is indicated by the solar terminator (black line, ground level) and nightside shading. Greenwich meridian longitude is the central vertical line in each image. Approximate geomagnetic field lines are centered on the 2005 Altitude-Adjusted Corrected Geomagnetic (AACGM) pole. Phase scintillation indices are plotted in area-scaled magenta points for each observed satellite within the hour of observation, at a subionospheric raypath pierce height of $250 \mathrm{~km}$ along the satellite track. Points having values greater than or equal to 0.3 are plotted as area-scaled white "bubbles" to emphasize stronger phase scintillation occurrence (elevation cutoff is 20 degrees, lock time $>240 \mathrm{~s}$ ). The sequence of TEC reconstructions shows the formation and lifetime of a plasma enhancement patch in the local dawn-midday sector, which breaks off the dayside plasma and drifts southward before dissipating. Phase scintillation appears coincident only in a temporal sense, with the exception of a possible spatial correlation at the break-off point in the 16:30 UTC image. 


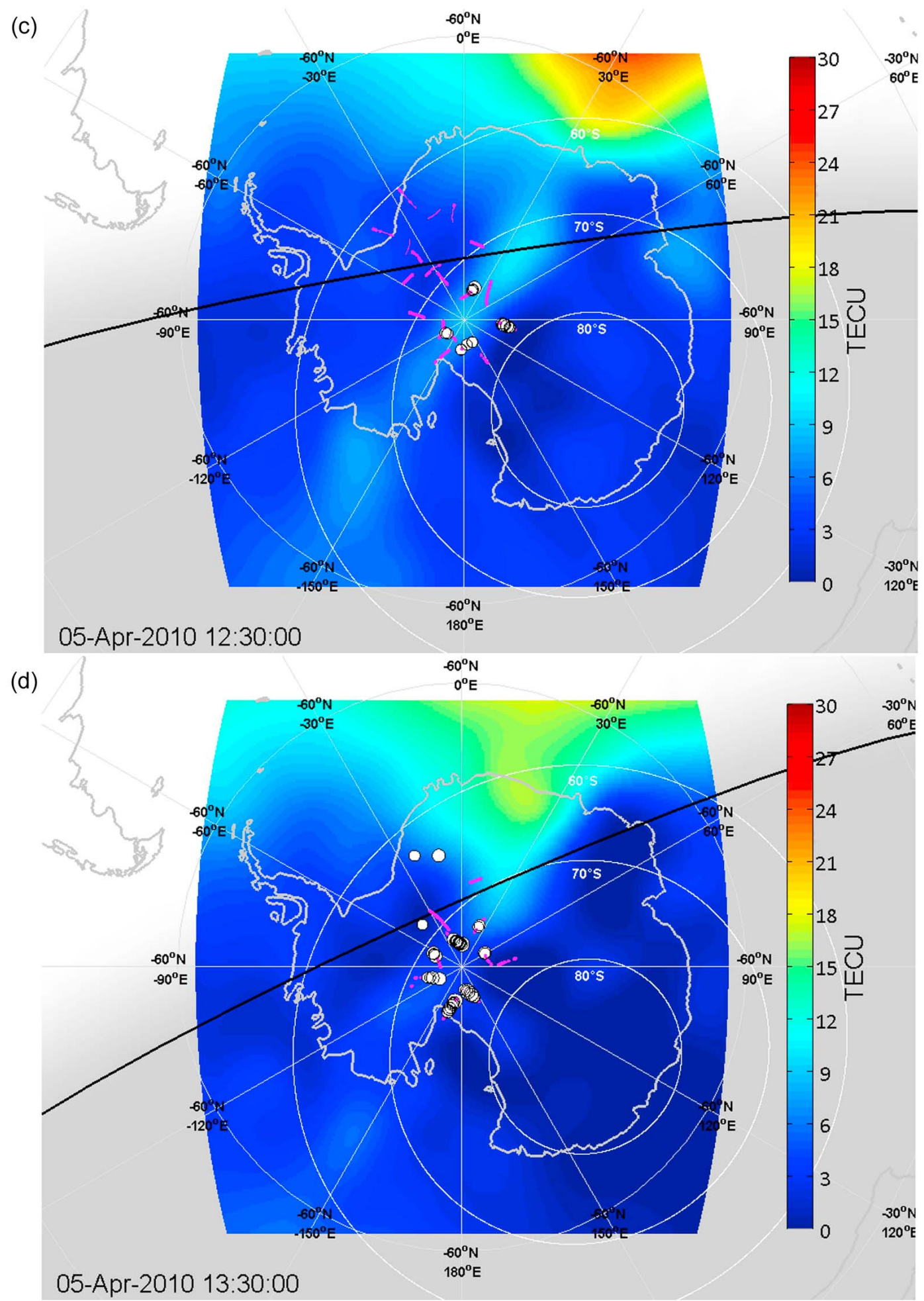

Figure 4. (continued) 
(e)
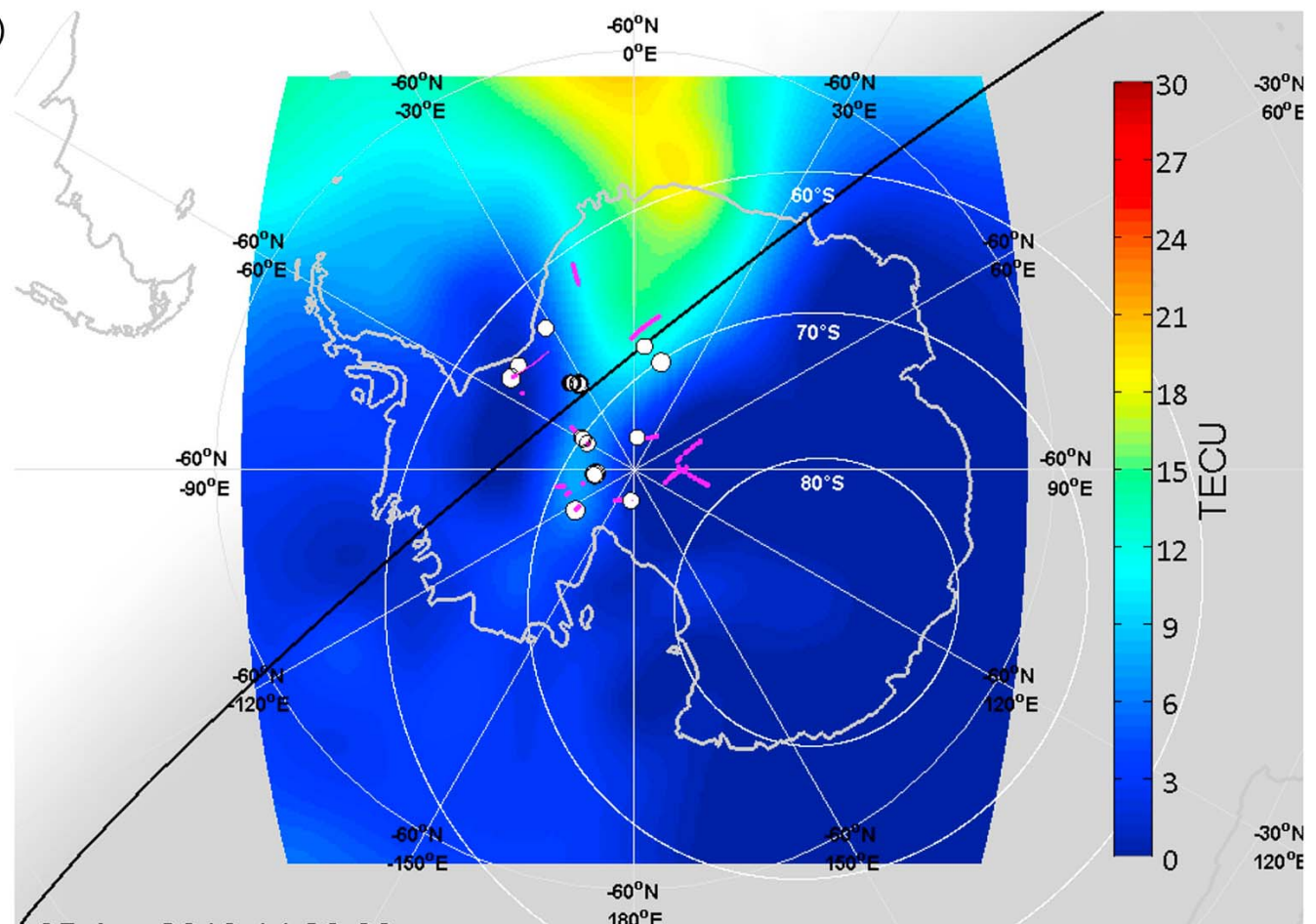

(f)

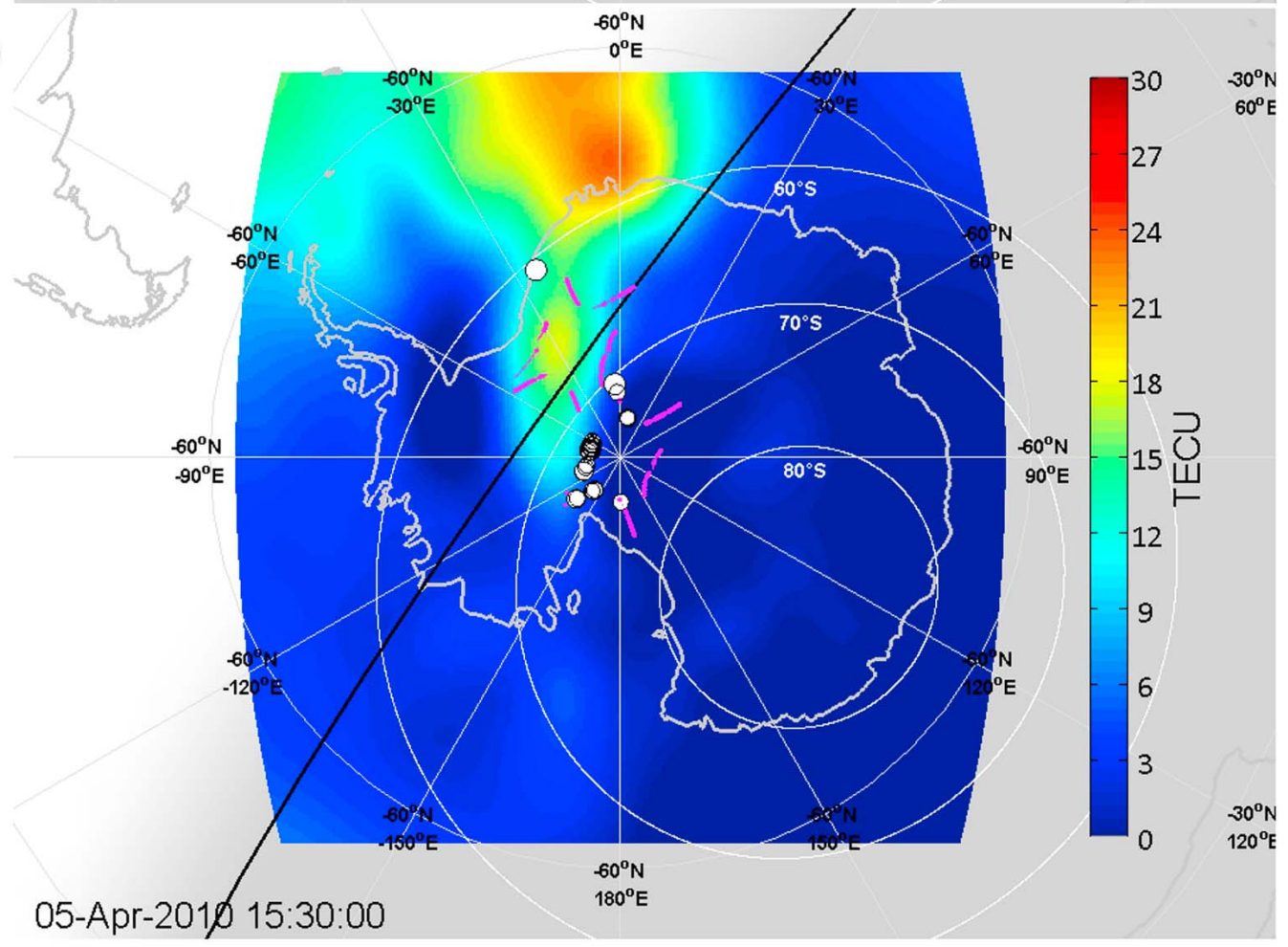

Figure 4. (continued) 


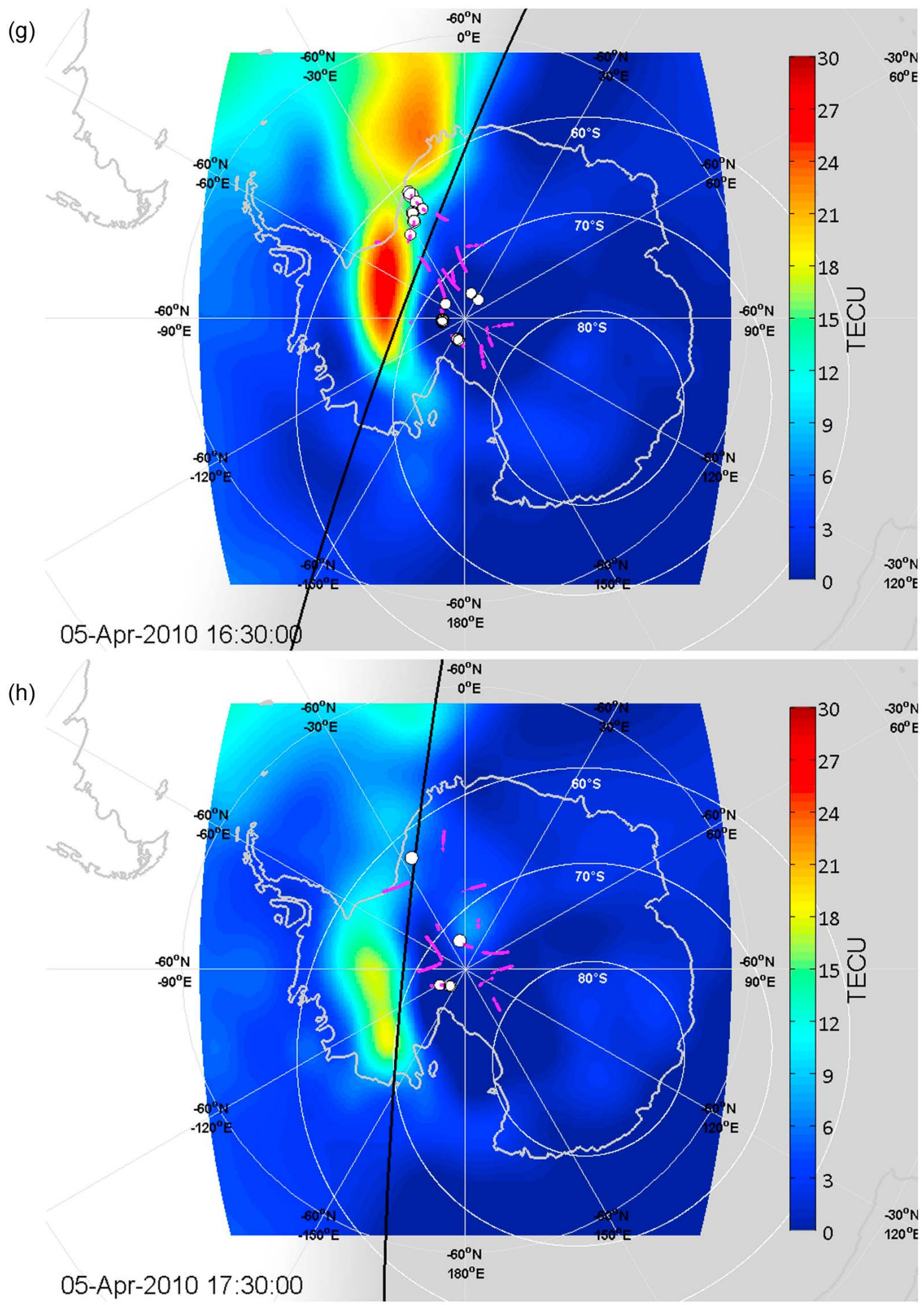

Figure 4. (continued) 


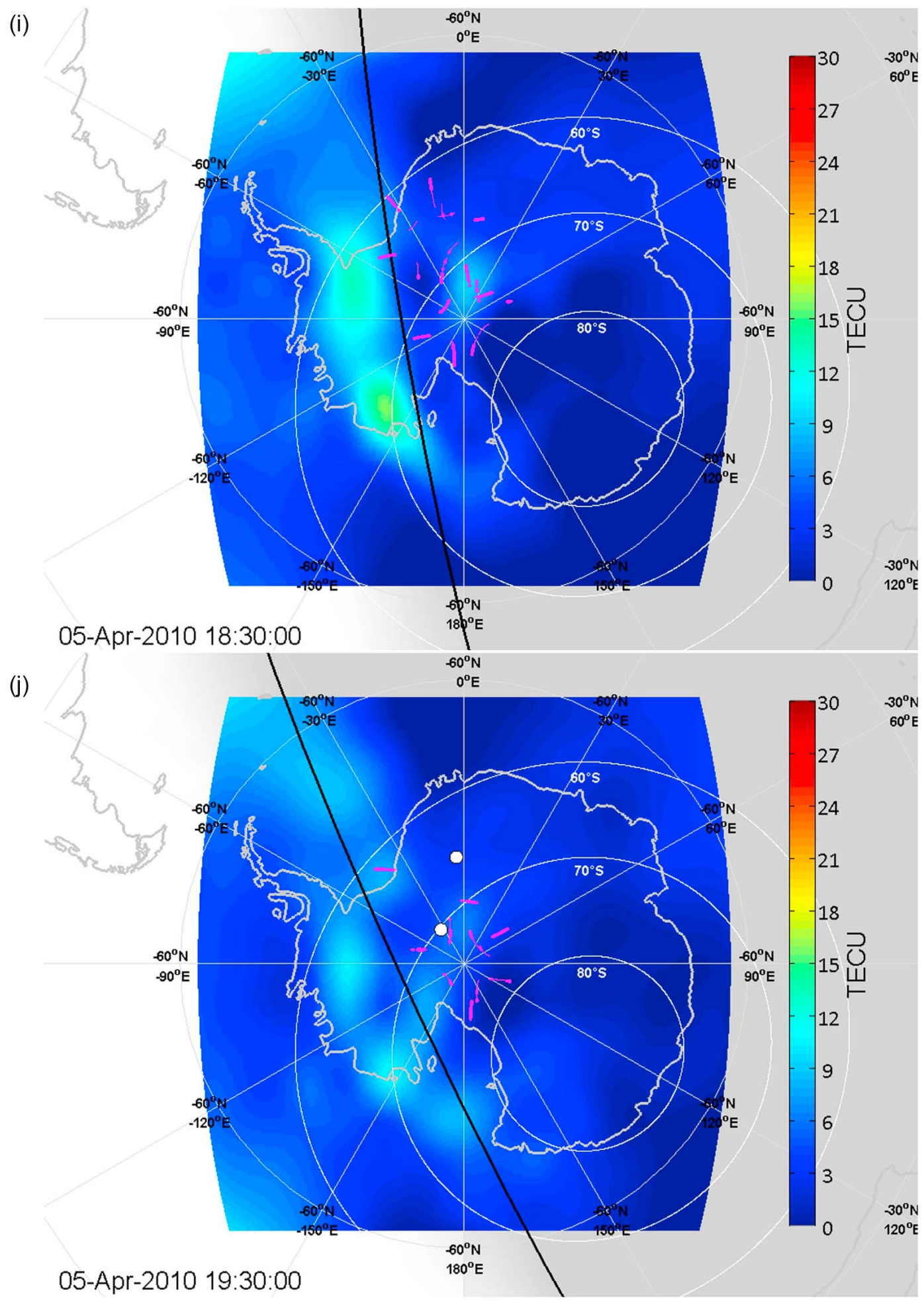

Figure 4. (continued) 
(a)

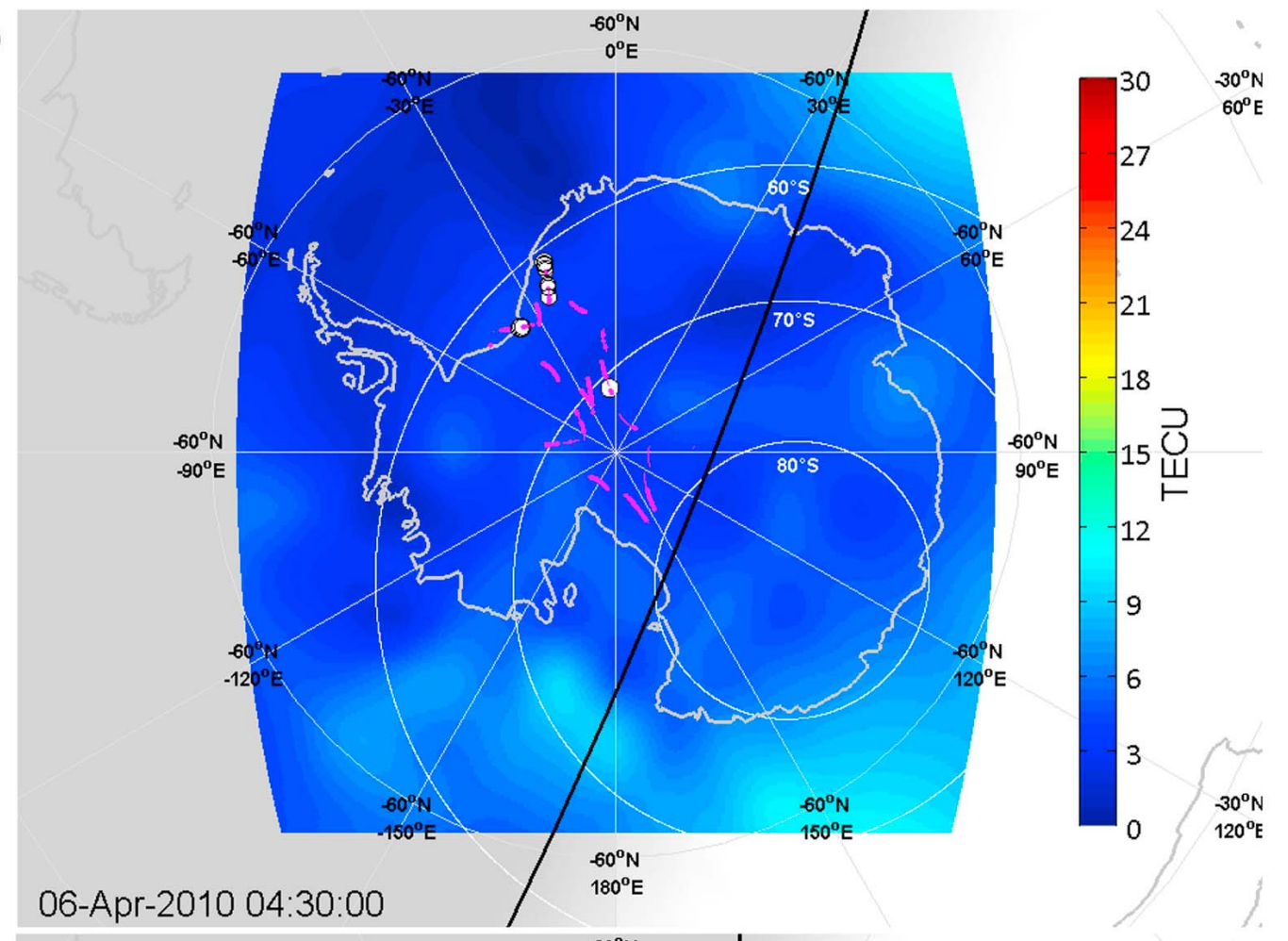

(b)

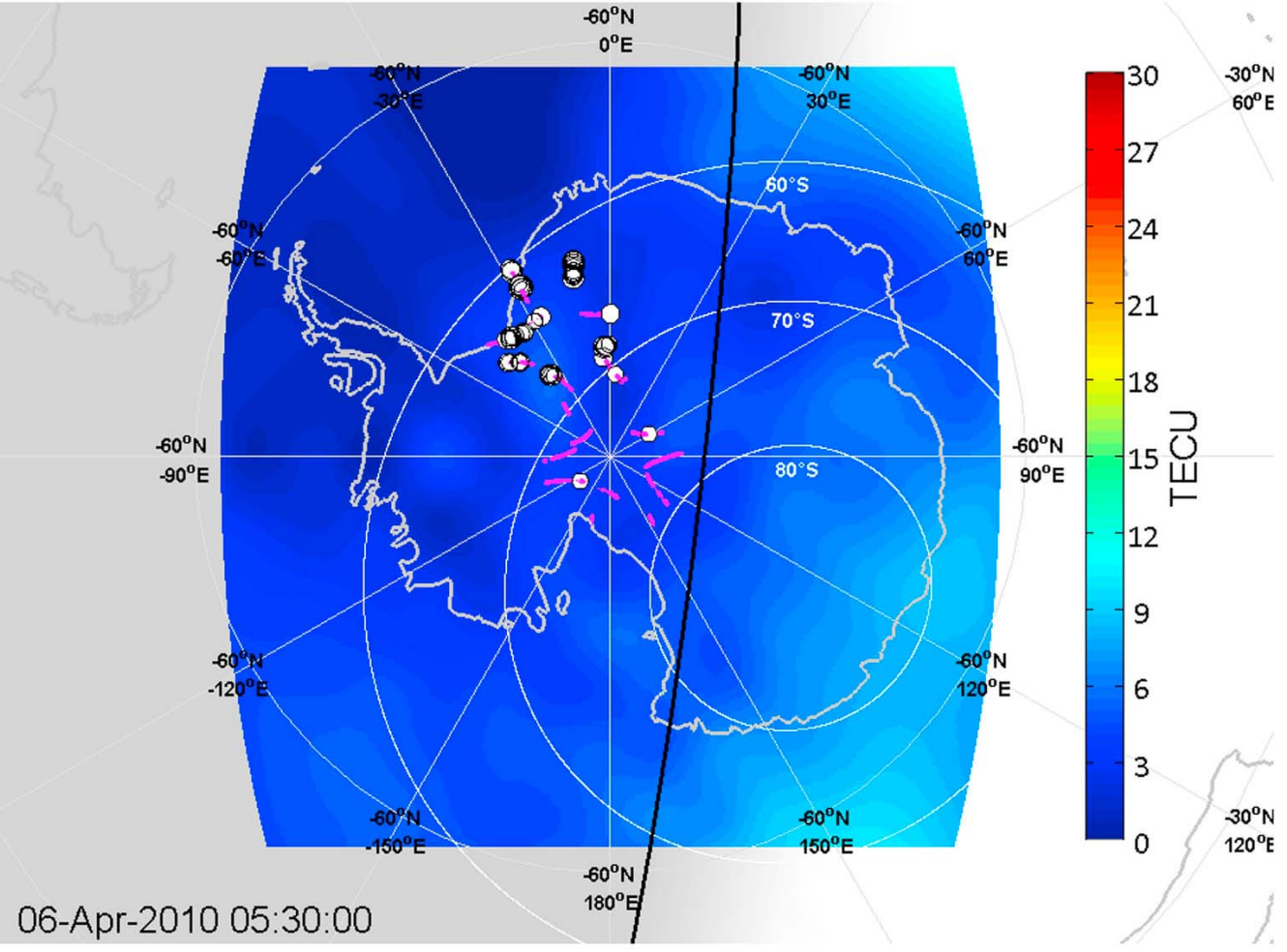

Figure 5. (a-f) A time series of ionospheric TEC images during 6 April 2010, overlaid with phase scintillation index variation from GPS receivers at the geographic South Pole and site Eagle. The TEC images suggest a relatively smooth ionosphere, absent of any large-scale plasma gradients. During the same time period, scintillation receivers at South Pole and site Eagle recorded moderate phase scintillation $\left(\sigma_{\phi}>0.3\right)$ on the majority of observed satellites within the dusk-midnight sector. 
(c)

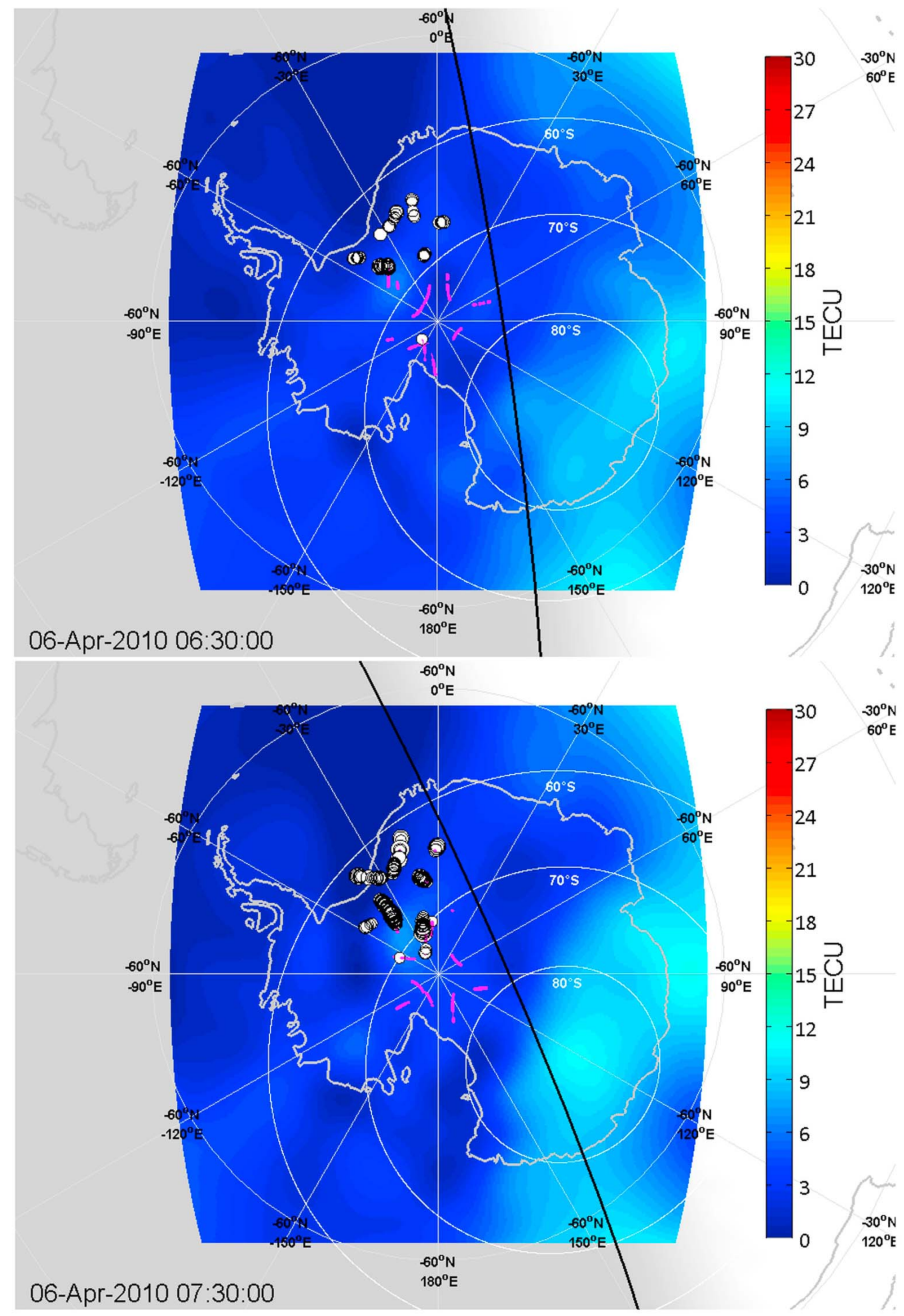

Figure 5. (continued) 
(e)

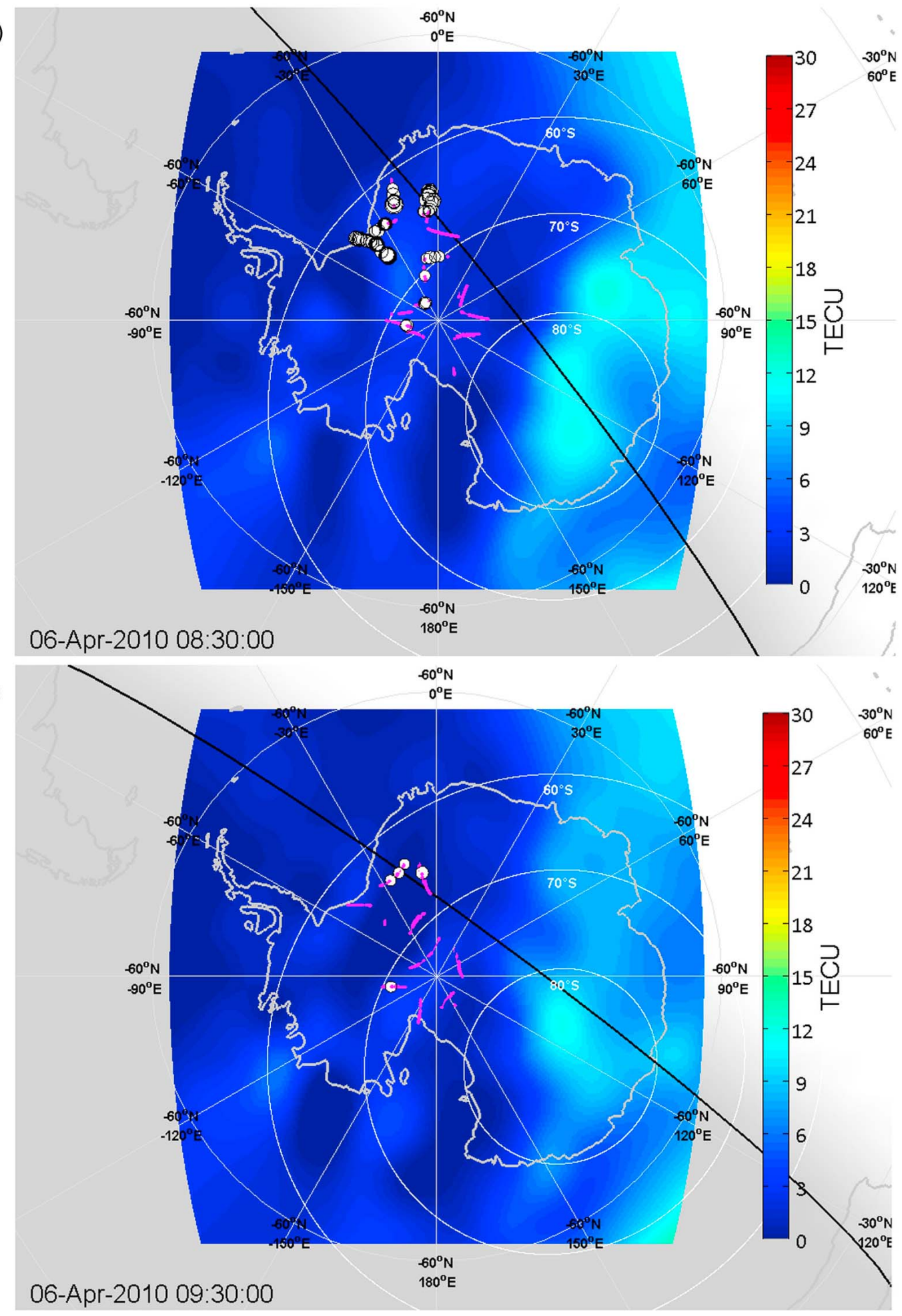

Figure 5. (continued) 


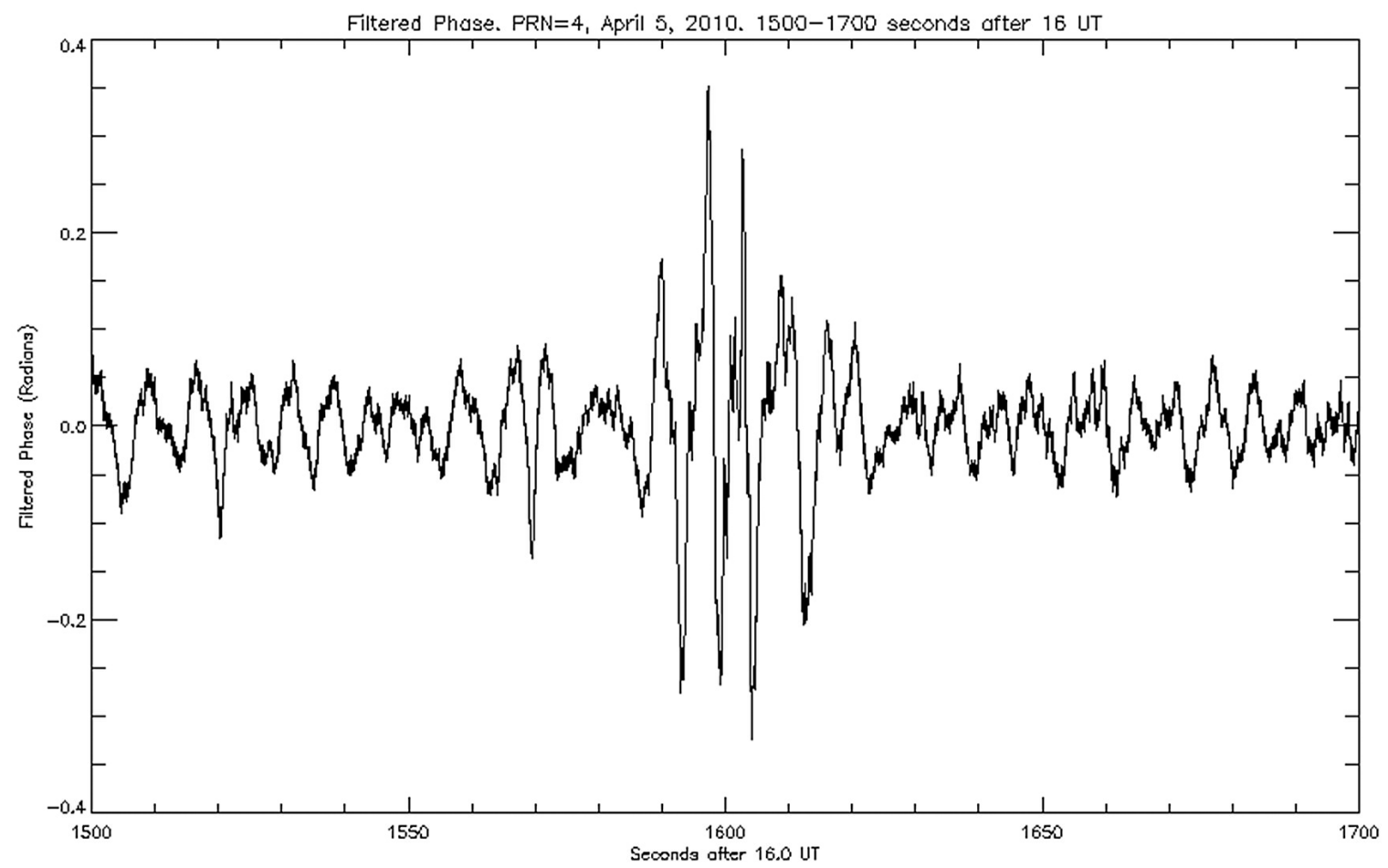

Figure 6. High data rate phase scintillations from PRN 4 recorded at South Pole during 1500-1700 s after 16:00 UTC on 5 April 2010. A $30 \mathrm{~s}$ burst period included several pseudoperiodic oscillations that lasted $\sim 5-6 \mathrm{~s}$. Similar signatures from other satellites during the same period suggest a source of signal diffraction fixed in magnetic local time for $\sim 30$ min, likely due to cusp precipitation.

this period, the ionosphere was unstructured in the region of scintillations and had low overall TEC values. Figure 8 presents a DMSP F18 pass from 06:30 to 06:40 UTC. The pass trajectory went right through the region of the scintillation observations, particularly the period from 06:33 to 06:37 UTC. During this period there were very high energies of electron precipitation $(>10 \mathrm{KeV})$, with high-energy flux, that extended across the region from $\sim 350^{\circ}$ to $293^{\circ}$ geographic longitude, and from $\sim 74^{\circ} \mathrm{S}$ to $80.4^{\circ} \mathrm{S}$ latitude. This suggests hard auroral precipitation that was probably directly causing kilometer-scale irregularities, which produced the observed phase scintillations. There was also a narrowly confined region of high-energy proton precipitation located at approximately $315^{\circ}$ longitude and $80^{\circ} \mathrm{S}$ latitude that appears to correlate well with some of the larger scintillations presented in Figure 5 for the 06:30 UTC and 07:30 UTC maps.

[23] Figure 9a shows a sample single-satellite time series of detrended $50 \mathrm{~Hz}$ L1 phase fluctuation during 07:04 UTC on 6 April 2010 at site Eagle; the low-frequency component due to satellite movement has been removed by a sixth-order Butterworth filter with cutoff frequency $0.1 \mathrm{~Hz}$. Figure $9 \mathrm{~b}$ shows an accompanying energy density spectrum of phase fluctuations from PRN 16, obtained by Fourier transform of $900050 \mathrm{~Hz}$ samples (3 min in time). Cycle fluctuations were occurring on a time scale of several seconds, implying that the ionospheric changes were of correspondingly longer time scales than those associated with classical diffractive scintillation. This is also supported by the phase scintillation spectrum (9b) that shows significant phase fluctuation occurrence at lower frequencies. It is likely that TEC gradients, associated with local precipitation energy input, were the cause of the phase scintillation in this case.

[24] Incoherent scatter radar measurements [Haldoupis et al., 2000; Yin et al., 2008; Mitchell et al., 1998] have previously shown that during strong precipitation events, enhancements in $E$ region electron density can reach up to $4 \times 10^{11}$ electrons per cubic meter over an extended altitude range. Projecting this electron density over, for example, an arbitrary $50 \mathrm{~km}$ vertical distance equates to $\sim 2.5$ TECU. Taking into account also the low-elevation nature of GPS raypath geometry at high latitudes, phase fluctuations such as those in Figure 9a could feasibly have arisen from $E$ region irregularities.

\subsection{Large-Scale Plasma Structuring}

[25] The time sequence of large-scale (hundreds of kilometers) plasma structuring in Figure 4 shows a plasma enhancement structure "breaking off" from the lower-latitude solar-produced plasma, resulting in a large southward drifting plasma patch and apparent depletion region at the break-off point. The reconstructed enhancement patch in the 16:30 UTC image of Figure 4 is approximately $1000 \mathrm{~km}$ long and $500 \mathrm{~km}$ wide; however $500 \mathrm{~km}$ is approaching the limit of the reconstruction resolution. The plasma depletion region is interesting since it occurred in the sunlit sector of the polar region, and appeared to be well equatorward of the cusp, within the auroral oval. It has been suggested above that the depletion region was due to enhanced recombination of $\mathrm{O}^{+}$due to soft electron precipitation. However, it is important to consider whether the depletion region could be an artifact of the tomographic imaging process, particularly 


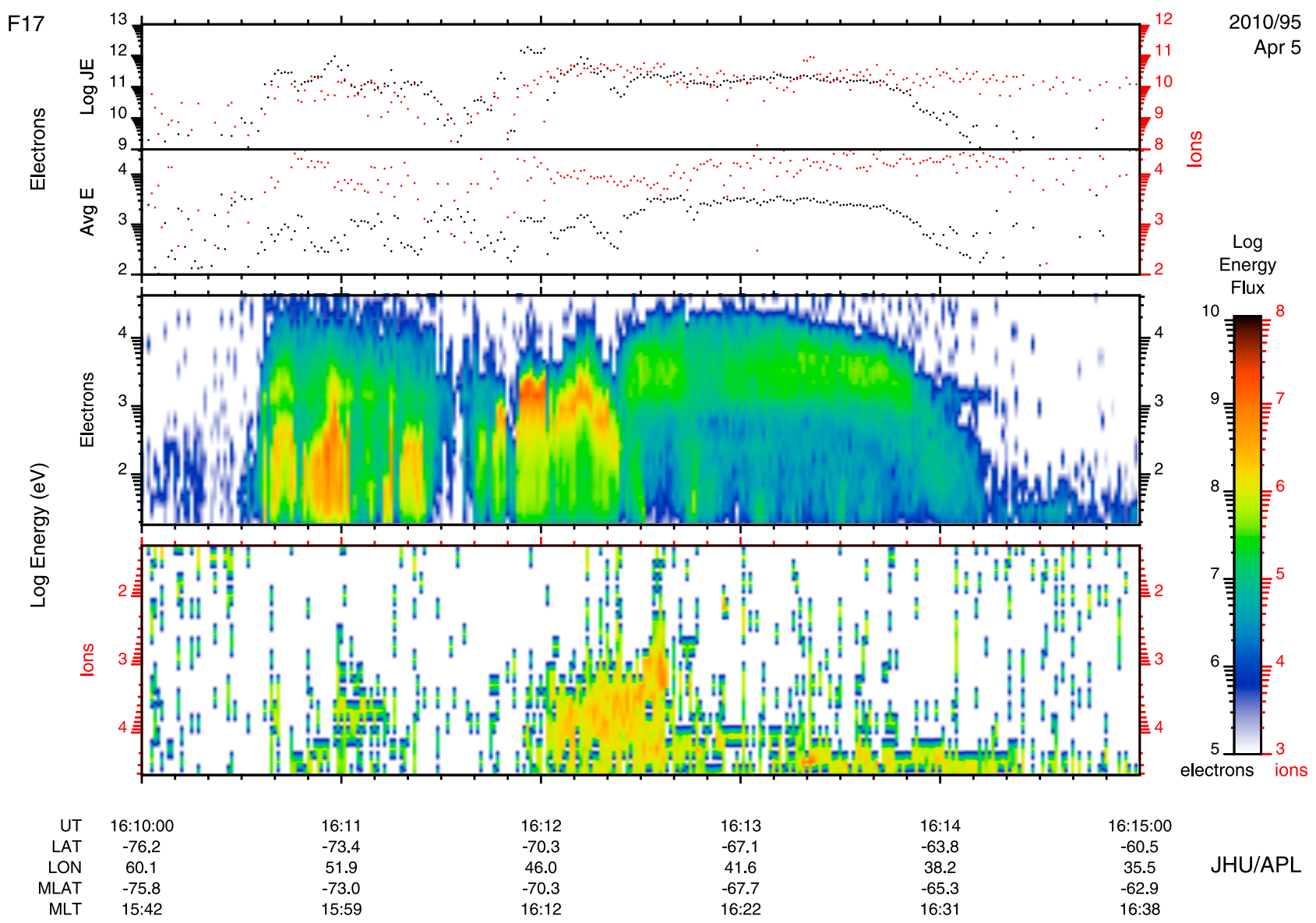

Figure 7. A particle spectrometer record from DMSP satellite F17 during 16:10-16:15 UTC, 5 April 2010. Labeled longitudes are eastern. Electron energies of $>1 \mathrm{KeV}$, proton energies of $1-10 \mathrm{KeV}$, and elevated energy flux levels indicate a period of hard $E$ region precipitation within a few sectors of MLT from the plasma enhancement patch break-off point.

because there is not an abundance of data in the Antarctic region. To address this issue, a completely separate imaging method, Ionospheric Data Assimilation Four-Dimensional (IDA4D) [Bust et al., 2004], based on data assimilation techniques, was run over the same time periods as MIDAS. For the 5 April 2010 analysis, IDA4D used International Reference Ionosphere (IRI) as a background initial model and ingested the same dual-frequency GPS data set from 50 sites shown in Figure 1; that is, identical raypath observations were processed by both MIDAS and IDA4D assimilation tools. In addition, IDA4D ingested TEC from the 55 ground Doppler Orbitography and Radio-positioning Integrated by Satellite (DORIS) stations, including four on the continent of Antarctica, LEO satellite occultation TEC from five Constellation Observing System for Meteorology, Ionosphere and Climate (COSMIC) satellites, LEO satellite topside TEC data from five COSMIC satellites and Satellite de Aplicaciones Cientifico-C (SAC-C). IDA4D uses a Gauss-Markov Kalman Filter to predict the solution forward in time.

[26] Figure 10 shows IDA4D specification of TEC over Antarctica at 16:45 UTC, overlaid with the data coverage ingested in its production. There is broad agreement with the MIDAS result shown in Figure 4. The two imaging methods use different algorithms and assumptions and further,
IDA4D has used radio occultation data from COSMIC. Of particular note is the improved data coverage in the IDA4D specification across the region of depletion in plasma entering the polar cap. This provides some confidence in the accuracy of the TEC maps.

[27] Further verification is provided by the GPS receivers on board the CHAMP and GRACE satellites. Figure 11a shows the upward looking vertical TEC projection above the CHAMP satellite altitude of $\sim 300 \mathrm{~km}$. It is clear that there is an enhancement of electron density in the topside ionosphere above the satellite in the vicinity of the plasma enhancement patch from the tomographic images. Figure $11 \mathrm{~b}$ shows a similar plot of vertical TEC for the GRACE satellite altitude of $\sim 480 \mathrm{~km}$. It is noted that the high altitude of the patch may be indicative of the Carlson et al. [2006] mechanism of formation. Thus, we believe the plasma enhancement region to be a real physical effect, most likely a result of antisunward plasma drift from a TOI separation being sustained by field-aligned soft electron precipitation.

\section{Conclusions}

[28] First results from a remote network of Antarctic GPS Ionospheric Scintillation and TEC Monitors have been presented in this paper. The scintillation receivers have operated 


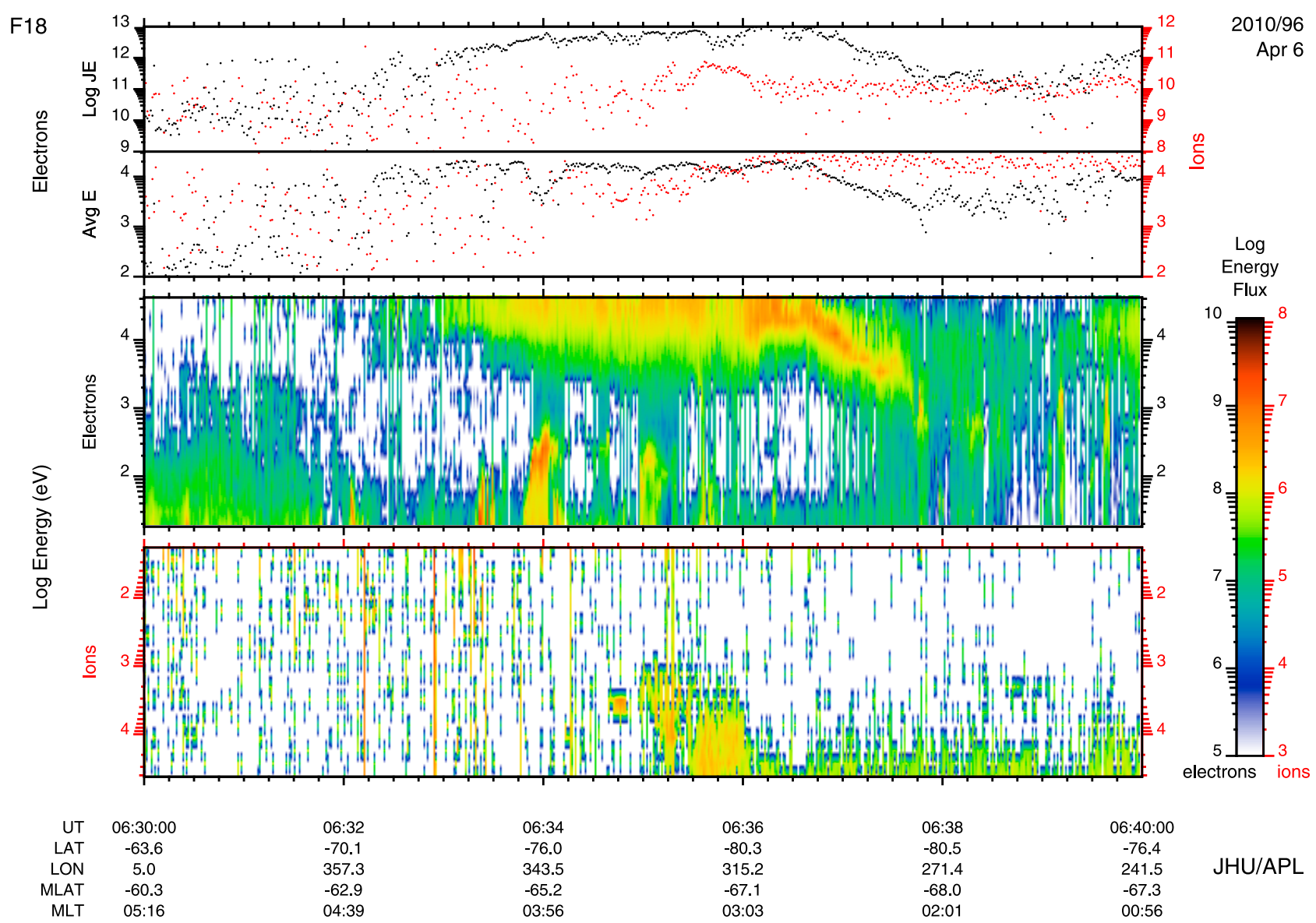

Figure 8. A particle spectrometer record from DMSP satellite F18 during 06:30-06:40 UTC, 6 April 2010. Very high electron energies $(>10 \mathrm{KeV})$ with high-energy flux are present, extending from $293^{\circ}$ to $350^{\circ}$ geographic longitude and $74^{\circ}-80^{\circ} \mathrm{S}$ geographic latitude, that is, in the observation area of site Eagle. This suggests hard auroral precipitation. Note also the short period of high-energy proton precipitation at $\sim 06: 35$ UTC.

remotely and over extended periods in the extreme environmental conditions of the central Antarctic plateau.

[29] An extended period of moderate GPS L1 phase scintillation has been identified at polar cap and auroral latitudes during 5 and 6 April 2010 in response to a coronal mass ejection (CME). The majority of observed satellites at the geographic South Pole displayed elevated $\sigma_{\varphi}$ indices during a 10 hour period from $\sim 08: 30$ UTC to 18:30 UTC. There was also significant phase scintillation at $81^{\circ} \mathrm{S}$ at site Eagle.

[30] TEC reconstruction images derived from GPS measurements have revealed the presence of a plasma enhancement patch structure during 5 April 2010, which formed and dissipated between the hours of $\sim 12: 00-19: 00$ UTC. Shortly after an IMF $B_{z}$ and $B_{y}$ change at UTC midday, plasma was transported poleward from sunlit midlatitudes and gradually separated as an isolated traveling structure moving in the convection pattern along the solar terminator. The plasma concentration remained largely within the local dawn-midday sector during the entirety of its lifetime. TEC from three semi-independent sources, the IDA4D assimilation tool and satellite passes from CHAMP and GRACE, have supported the presence of this plasma structure.

[31] Superposition of phase scintillation indices onto the MIDAS TEC images has allowed the examination of spatial and temporal correlation with plasma gradients associated with the plasma enhancement structure. Phase scintillation was present throughout both days and was not necessarily associated with plasma gradients. However, there was one notable time between 16:00 and 17:00 UTC on the first day when there was evidence of spatial association between a depletion region at the plasma enhancement break-off region and the phase scintillation.

[32] There were limited DMSP satellite passes in close proximity to the scintillation regions. However, the passes of DMSP and POES did show general elevated levels of electron and ion temperature and energy, indicating that there was precipitation into the polar cap.

[33] Three distinct scintillation events were identified. In the first, soon after the CME, there were phase scintillations associated with the dayside cusp confined to a short MLT window. They occurred in short bursts of $\sim 30 \mathrm{~s}$, with 4-5 clear oscillations. The second event was associated with a sunlit TEC depletion region where the plasma enhancement structure entered the polar cap and separated from the dayside plasma. The third event was on the nightside on the second day, where elevated levels of phase scintillation were observed in a region of low TEC. 
(a)

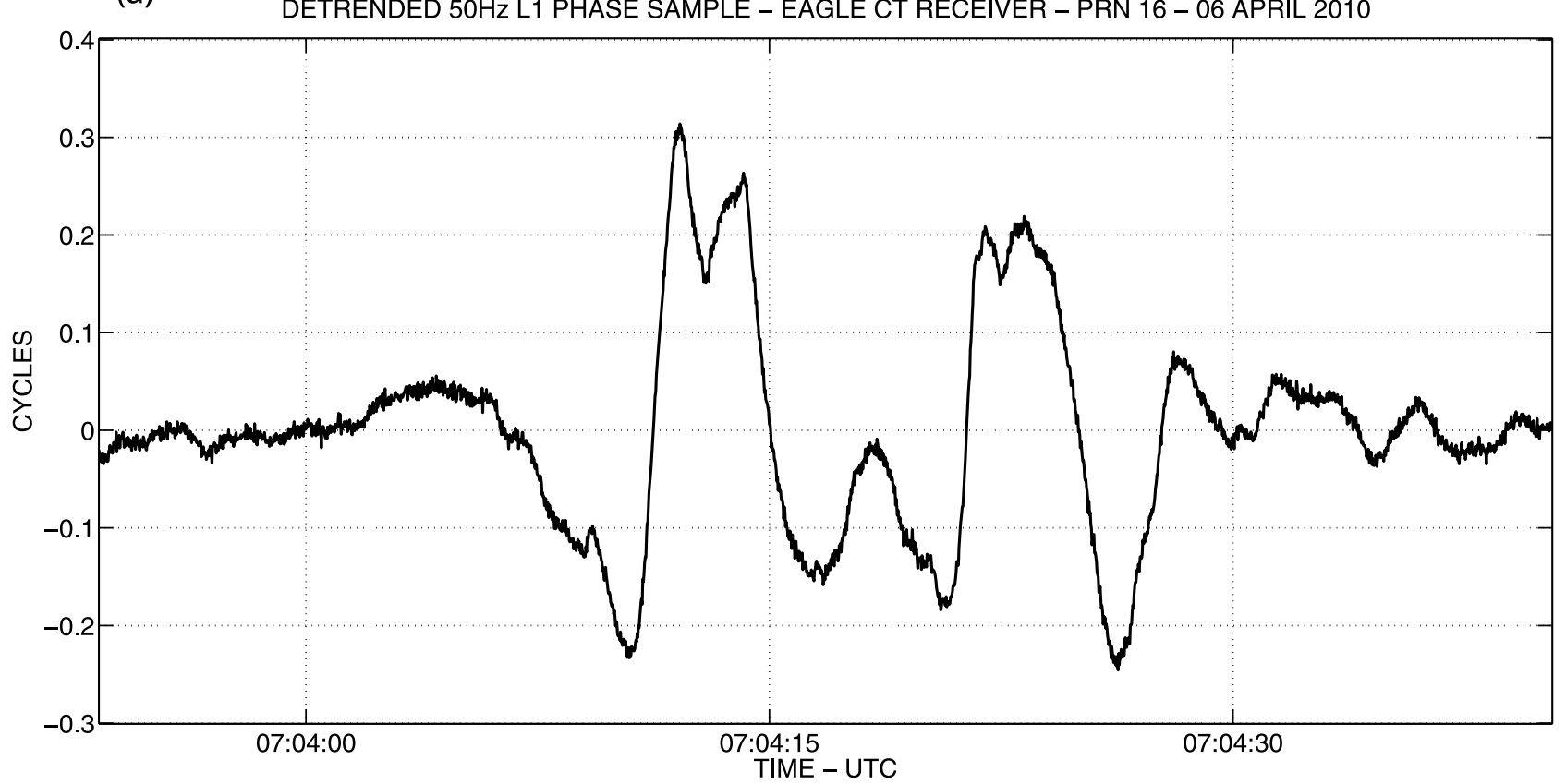

(b)

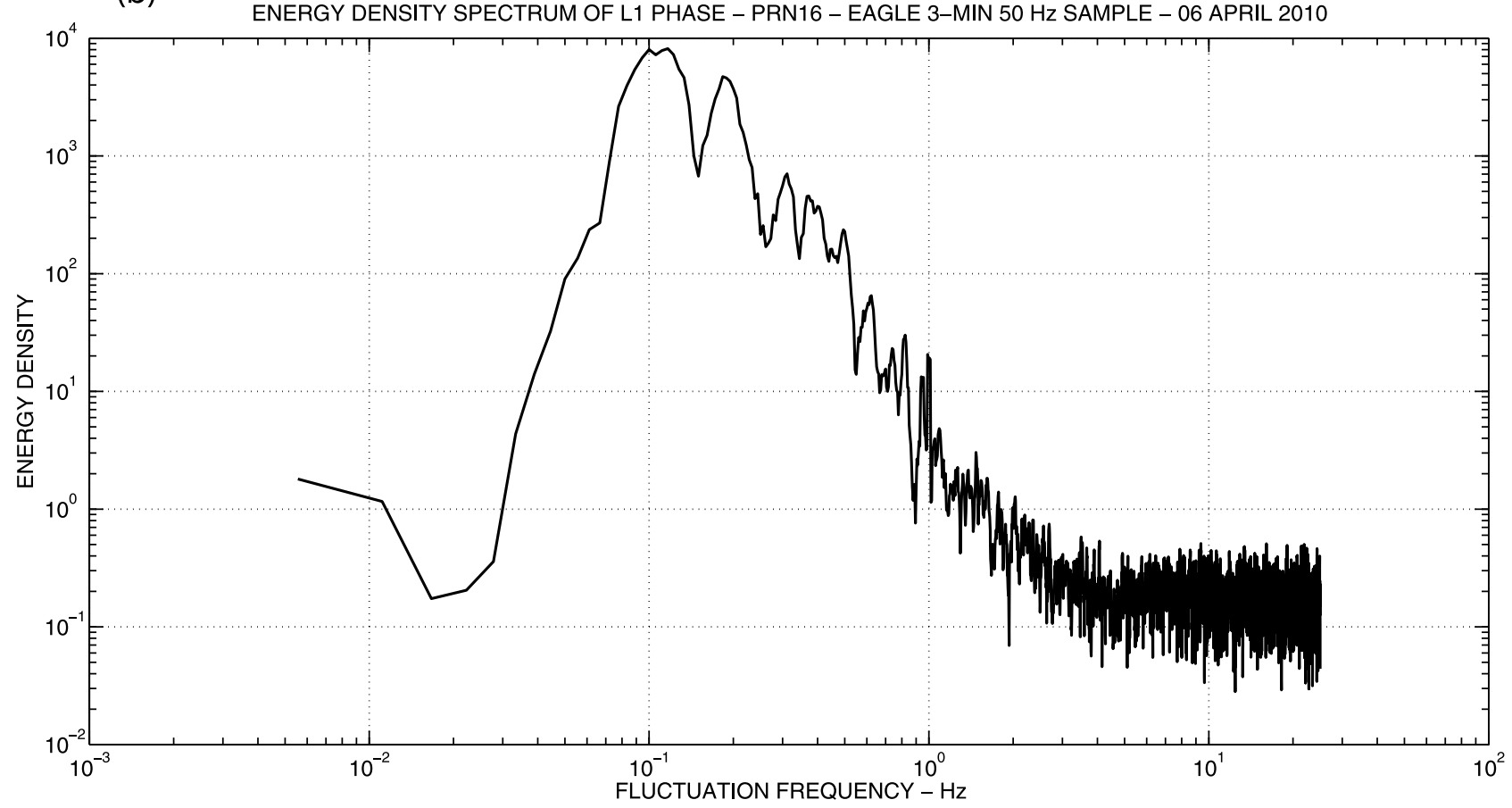

Figure 9. (a) A sample of detrended $50 \mathrm{~Hz} \mathrm{L1}$ phase fluctuation from PRN16 recorded at site Eagle during 07:04 UTC on 6 April 2010 and (b) accompanying smoothed energy density spectrum of the phase fluctuation using a total of 9000 samples around this time. Detrending was performed using a high-pass sixth-order Butterworth filter with cutoff frequency of $0.1 \mathrm{~Hz}$. Cycle fluctuations were occurring on a time scale of several seconds, implying that the ionospheric changes were of correspondingly longer time scales than those associated with classical diffractive scintillation. 


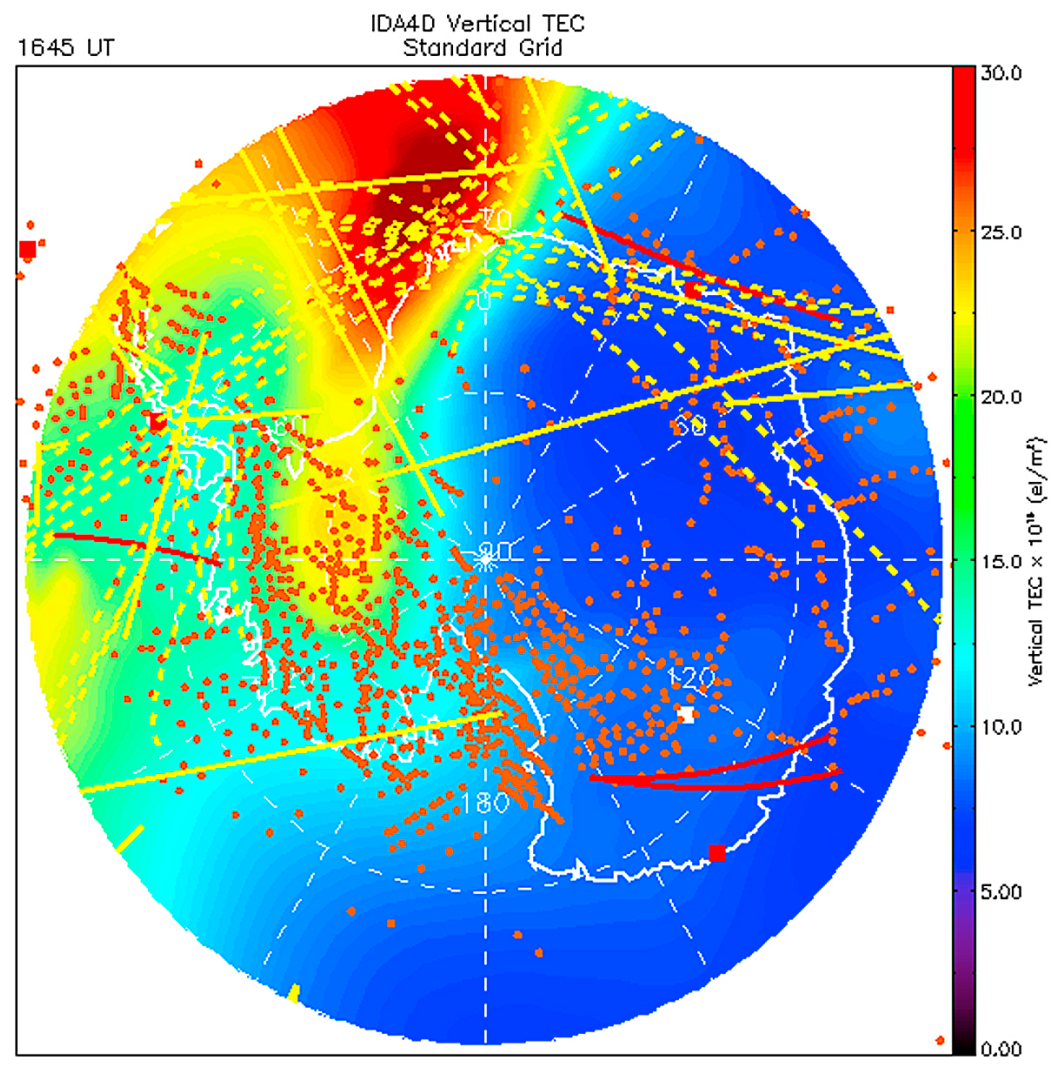

Figure 10. IDA4D TEC image over Antarctica at 16:45 UTC on 5 April 2010, overlaid with ingested data coverage. Solid yellow lines show COSMIC occultation intercepts (derived from the longest great circle paths between receiver and satellite, along the occultation trajectory up to $800 \mathrm{~km}$ altitude). Orange dots represent GPS raypath intercepts at $350 \mathrm{~km}$. Dashed yellow lines show topside TEC intercepts at $1000 \mathrm{~km}$ from COSMIC, CHAMP, and GRACE. Red squares and lines show DORIS coverage at $350 \mathrm{~km}$ intercepts. This reconstruction used GPS raypath observations that were identical to the MIDAS method, with the addition of TEC input from DORIS, COSMIC, and SAC-C instruments and a Kalman filter approach. 
(a)

CHAMP VTEC 1600-1625 UT

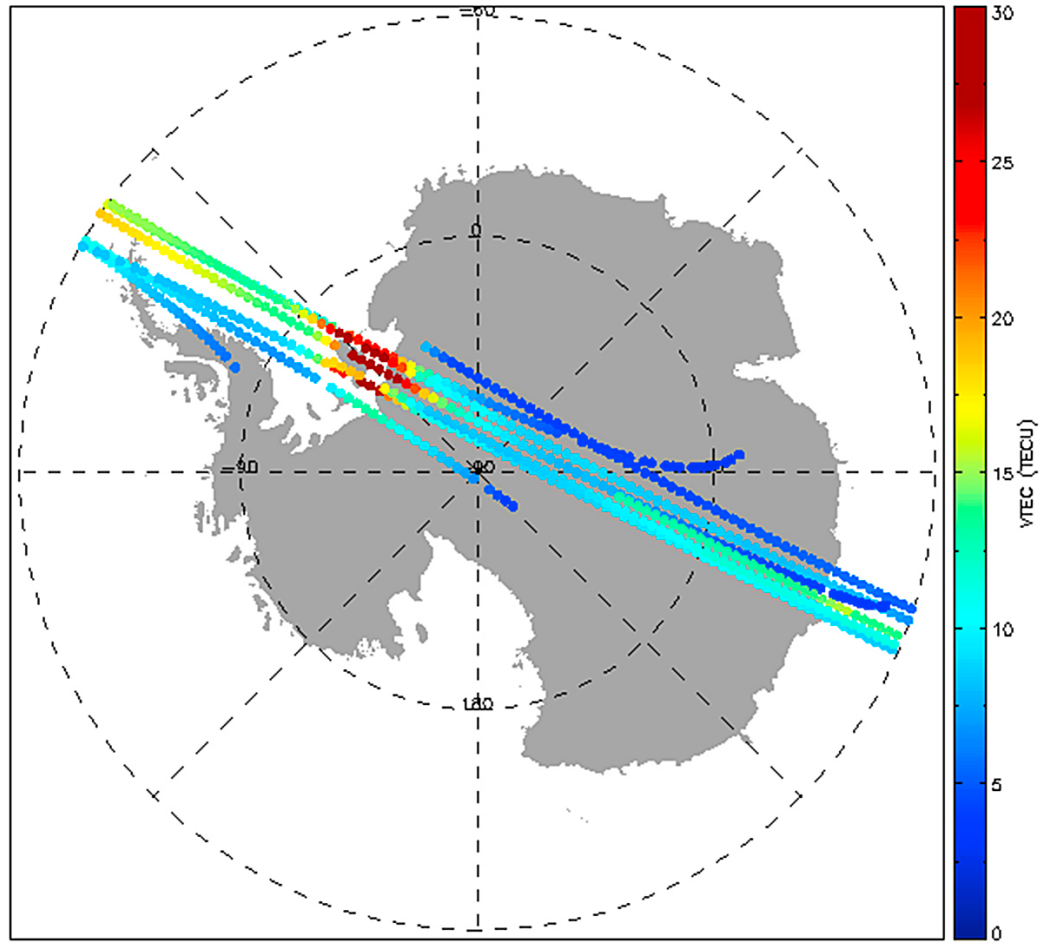

(b)

GRACE VTEC 1615-1645 UT

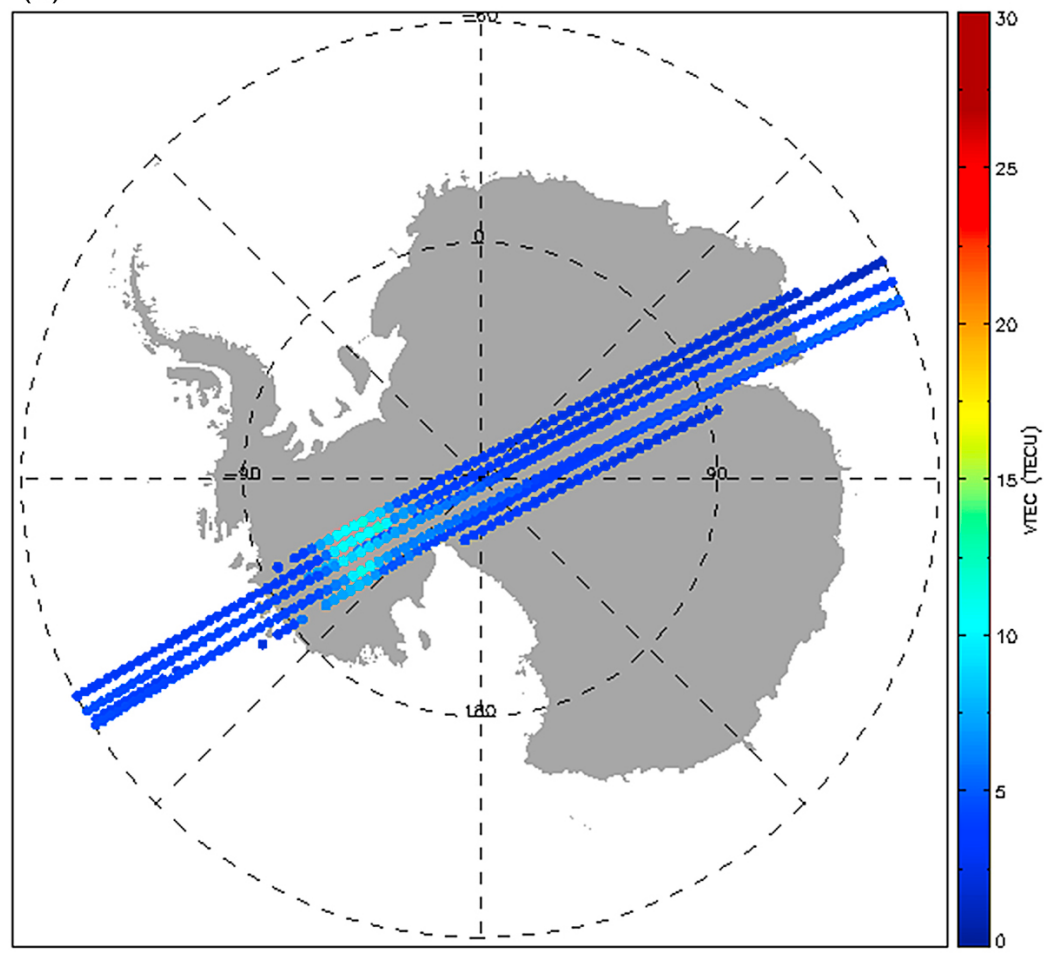

Figure 11. GPS vertical TEC projections over Antarctica (a) above the CHAMP satellite between 16:15 and 16:45 UTC and (b) above the GRACE satellite between 16:00 and 16:25 UTC. Both show enhancements in TEC at the crossing of the plasma enhancement patch, with the GRACE levels slightly lower owing to its orbital altitude above the bulk of the $F$ region. 
[34] Previous studies from the Arctic have indicated a number of mechanisms for scintillation on GPS signals, for example cusp precipitation, auroral precipitation and gradient drift/turbulence. This study from the Antarctic indicates that the most likely cause of scintillation during this storm is particle precipitation causing irregularity structuring on both the dayside and the nightside ionospheres.

[35] Acknowledgments. We thank the Engineering and Physical Sciences Research Council, the Isle of Man Government, and the Natural Environment Research Council for funding this project, and we thank the British Antarctic Survey and the United States Antarctic Program for their extensive logistical and engineering support. Ping Yin is grateful for support from a special grant of the Civil Aviation University of China (ZXH2009B005). G. S. Bust was supported under NSF grants ANT0840650 and ANT-0839858. South Pole GPS operations are supported in part by NSF grants ANT- 0840158 and ANT-0638587 to Siena College. These awards further support the University of Bath/Siena College GPS collaboration at South Pole and McMurdo Stations, Antarctica. GPS ground data from the PoleNet and IGS campaigns were obtained through the UNAVCO facility with support from the National Science Foundation and the NASA under NSF cooperative agreement EAR-0735156. We gratefully acknowledge the ACE MAG instrument team and the ACE Science Center for providing IMF data, the National Oceanic and Atmospheric Administration for providing magnetic indices through the SPIDR facility, the Center for Space Sciences at the University of Texas at Dallas and the U.S. Air Force for providing the DMSP thermal plasma data, the Auroral Particles and Imagery Group at the Johns Hopkins University Applied Physics Laboratory for providing DMSP particle spectrometer data, and the German Research Centre for Geosciences at GFZ Potsdam for providing CHAMP and GRACE satellite data.

[36] Robert Lysak thanks Chigomezyo Ngwira and another reviewer for their assistance in evaluating this paper.

\section{References}

Basu, S., K. M. Groves, S. Basu, and P. J. Sultan (2002), Specification and forecasting of scintillations in communication/navigation links: Curren status and future plans, J. Atmos. Sol. Terr. Phys., 64, 1745-1754, doi:10.1016/S1364-6826(02)00124-4.

Burston, R., I. Astin, C. N. Mitchell, L. Alfonsi, T. Pedersen, and S. Skone (2009), Correlation between scintillation indices and gradient drift wave amplitudes in the northern polar ionosphere, J. Geophys. Res., 114, A07309, doi:10.1029/2009JA014151.

Bust, G. S., T. W. Garner, and T. L. Gaussiran II (2004), Ionospheric Data Assimilation Three-Dimensional (IDA4D): A global, multisensor, electron density specification algorithm, J. Geophys. Res., 109, A11312, doi:10.1029/2003JA010234.

Carlson, H. C., J. Moen, K. Oksavik, C. P. Nielsen, I. W. McCrea, T. R. Pedersen, and P. Gallop (2006), Direct observations of injection events of sub-auroral plasma into the polar cap, Geophys. Res. Lett., 33 , L05103, doi:10.1029/2005GL025230.

Fremouw, E. J., J. A. Secan, and C. Zhou (1997), Tailoring of EOFs for ionospheric tomography and the weighted, partitioned, least-squares algorithm, Acta Geod. Geophys. Hung., 32(3-4), 365-377.

Haldoupis, C., K. Schlegel, and G. Hussey (2000), Auroral $E$ region electron density gradients measured with EISCAT, Ann. Geophys., 18 , 1172-1181, doi:10.1007/s00585-000-1172-x.

Hunsucker, R. D., and J. K. Hargreaves (2003), The high-latitude $F$ region and the trough, in The High-Latitude Ionosphere and Its Effects on Radio Propagation, pp. 227-281, Cambridge Univ. Press, Cambridge, U. K.

Mitchell, C. N., I. K. Walker, S. E. Pryse, I. Kersley, I. W. McCrea, and T. B. Jones (1998), First complementary observations by ionospheric tomography, the EISCAT Svalbard radar and the CUTLASS HF radar, Ann. Geophys., 16, 1519-1522, doi:10.1007/s00585-998-1519-2.

Mitchell, C. N., L. Alfonsi, G. De Franceschi, M. Lester, V. Romano, and A. W. Wernik (2005), GPS TEC and scintillation measurements from the polar ionosphere during the October 2003 storm, Geophys. Res. Lett., 32, L12S03, doi:10.1029/2004GL021644.

Möstl, C., M. Temmer, T. Rollett, C. J. Farrugia, Y. Liu, A. M. Veronig M. Leitner, A. B. Galvin, and H. K. Biernat (2010), STEREO and Wind observations of a fast ICME flank triggering a prolonged geomagnetic storm on 5-7 April 2010, Geophys. Res. Lett., 37, L24103, doi:10.1029/2010GL045175.

Ngwira, C. M., L. McKinnell, and P. J. Cilliers (2010), GPS phase scintillation observed over a high-latitude Antarctic station during solar minimum, J. Atmos. Sol. Terr. Phys., 72, 718-725, doi:10.1016/j. jastp.2010.03.014.

Pokhotelov, D., P. T. Jayachandran, C. N. Mitchell, and M. H. Denton (2010), High-latitude ionospheric response to co-rotating interaction region- and coronal mass ejection-driven geomagnetic storms revealed by GPS tomography and ionosondes, Proc. R. Soc. London, Ser. A, 466(2123), 3391-3408, doi:10.1098/rspa.2010.0080.

Prikryl, P., P. T. Jayachandran, S. C. Mushini, D. Pokhotelov, J. W. MacDougall, E. Donovan, E. Spanswick, and J.-P. St.-Maurice (2010), GPS TEC, scintillation and cycle slips observed at high latitudes during solar minimum, Ann. Geophys., 28, 1307-1316, doi:10.5194/angeo-28$1307-2010$

Smith, A. M., C. N. Mitchell, R. J. Watson, R. W. Meggs, P. M. Kintner, K. Kauristie, and F. Honary (2008), GPS scintillation in the high arctic associated with an auroral arc, Space Weather, 6, S03D01, doi:10.1029/ 2007SW000349.

Spencer, P. S. J., and C. N. Mitchell (2007), Imaging of fast moving electron-density structures in the polar cap, Ann. Geophys., 50, 427-434 Spogli, L., L. Alfonsi, G. De Franceschi, V. Romano, M. H. O. Aquino, and A. Dodson (2009), Climatology of GPS ionospheric scintillations over high and mid-latitude European regions, Ann. Geophys., 27, 3429-3437, doi:10.5194/angeo-27-3429-2009.

Valladares, C., S. Basu, J. Buchau, and E. Friis-Christensen (1994), Experimental evidence for the formation and entry of patches into the polar cap, Radio Sci., 29, 167-194, doi:10.1029/93RS01579.

Van Dierendonck, A. J. (1999), Eye on the ionosphere: Measuring ionospheric scintillation events from GPS signals, GPS Solutions, 2(4), 60-63, doi:10.1007/PL00012769.

Yeh, K. C., and C.-H. Liu (1982), Radio wave scintillations in the ionosphere, Proc. IEEE, 70(4), 324-360, doi:10.1109/PROC.1982.12313.

Yin, P., C. N. Mitchell, P. Spencer, and T. Pedersen (2008), A multidiagnostic approach to understanding high-latitude plasma transport during the Halloween 2003 storm, Ann. Geophys., 26, 2739-2747, doi:10.5194/angeo-26-2739-2008

Yin, P., et al. (2009), Imaging of the Antarctic ionosphere: Experimental results, J. Atmos. Sol. Terr. Phys., 71, 1757-1765, doi:10.1016/j. jastp.2009.09.014

G. S. Bust, Atmospheric and Space Technology Research Associates, LLC, 5777 Central Ave., Ste. 221, Boulder, CO 80301, USA.

M. J. Jarvis, D. J. Maxfield, and M. C. Rose, Physical Sciences Division, British Antarctic Survey, High Cross, Madingley Road, Cambridge CB3 OET, UK

J. Kinrade, C. N. Mitchell, and N. Smith, Department of Electronic and Electrical Engineering, University of Bath, Claverton Down, Bath, Somerset BA2 7AY, UK. (j.kinrade@bath.ac.uk)

A. T. Weatherwax, Department of Physics, Siena College, 515 Loudon Rd., Loudonville, NY 12211-1462, USA.

P. Yin, College of Electronic Information Engineering, Civil Aviation University of China, Tianjin 618307, China. 